\section{A) Check for updates}

Cite this: Nanoscale, 2021, 13, 9091

\title{
Mesoporous silica nanoparticles as carriers of active agents for smart anticorrosive organic coatings: a critical review
}

\author{
Federico Olivieri, (D) a Rachele Castaldo, (D) a Mariacristina Cocca, (D) ${ }^{a}$ \\ Gennaro Gentile (ID *a and Marino Lavorgna (D) ${ }^{b}$
}

\begin{abstract}
Mesoporous silica nanoparticles (MSN) have attracted increasing interest for their applicability as smart nanocarriers of corrosion inhibitors, due to their porous structure, resistance to main corrosive environments and good compatibility with polymer coatings. In this review, the main synthetic routes to obtain MSN with tailored textural properties, the design of different loading and stimuli-induced release strategies, the development of advanced organic nanocomposite coatings with MSN and the validation of their anticorrosive performances are reviewed and compared. Through a critical analysis of the literature, the most promising research trends and perspectives to exploit the highly interesting properties of MSN in advanced organic coatings are proposed.
\end{abstract}

Received 25th March 2021, Accepted 5th May 2021

DOI: $10.1039 / \mathrm{d} 1 \mathrm{nr} 01899$ j rsc.li/nanoscale high surface area inorganic nanocarriers are very attractive as smart corrosion inhibitors nanocontainers and, among them, mesoporous silica nanoparticles (MSN) have a prominent role in the design of innovative and smart nanocomposite coatings.

MSN are a class of materials widely investigated for several applications, ranging from energy storage, ${ }^{7,8}$ water and air purification, ${ }^{9-14}$ catalysis $^{15,16}$ optoelectronics, ${ }^{17}$ drug delivery ${ }^{18,19}$ or smart release of active agents. ${ }^{20-22}$ For coating applications, MSN have several advantages, such as a chemically stable structure, low reactivity and compatibility with numerous matrices. ${ }^{6,23}$ Moreover, MSN are currently quite easily synthesized ${ }^{24}$ and their high surface area and mesoporous structure are very attractive for adsorption and desorption related applications. Indeed, adsorption is a phenomenon involving the enrichment of a fluid on the surface of an adsorbent, and thus, the most important requirement for a good adsorbent is a large specific surface area. Whether adsorption is induced by long-range interactions (physisorption) or by chemical interactions, such as covalent or ionic bonds (chemisorption), the porosity of the adsorbents outlines their adsorption properties. Physical adsorption, in particular, is favoured in pores whose dimensions are comparable to the adsorptive molecular radius and, for this reason, materials prevalently characterized by micropores and small mesopores are typically considered good adsorbents. ${ }^{25-27}$

However, when MSN are employed as nanocontainers of anticorrosive agents in high performance coatings, both the loading of active agents and their stimuli-responsive release must be carefully investigated. In order to maximize the
${ }^{a}$ Institute for Polymers, Composites and Biomaterials, National Research Council of
Italy, Via Campi Flegrei 34, 80078 Pozzuoli, Italy. E-mail: gennaro.gentile@cnr.it
${ }^{b}$ Institute for Polymers, Composites and Biomaterials, National Research Council of
Italy, P.le E. Fermi 1, 80055 Portici, Italy 
loading of the corrosion inhibitors into the porous nanocarriers, various approaches can be followed. First of all, inhibitor dimension and chemistry have to be considered. The nanocarrier porosity should be tailored in order to contain sufficient amount of active agents and to ease the penetration of the inhibitor into the porous structure. ${ }^{28-32}$ Loading capability is a fundamental point to ensure a promising anticorrosive behaviour of the smart system. Moreover, the chemical interactions between the nanocarrier and the inhibitor have to be properly designed and tailored, in order to promote the inhibitor release at the right moment. ${ }^{33,34}$ Indeed, nanocarriers must contain the loaded inhibitor for a reasonable time and have a stable chemical structure in the environment wherein they are applied. ${ }^{35}$

As it will be detailed in the next sections of this review, the competitive advantages of coatings realized by embedding MSN as corrosion inhibitors nanocarriers over coatings containing free corrosion inhibitors can be ascribed to the following MSN key properties:

(1) Due to their high porosity, MSN can load high amounts of active agents (i.e. anticorrosive agents), allowing to overcome their solubility limit when used in polymeric coatings;

(2) Various corrosion inhibitors can be loaded into MSN, almost irrespectively on their chemical nature and properly selected on the basis of the degradation mechanism of the substrate to be protected;

(3) By loading the corrosion inhibitors into MSN, also active agents that are not miscible with the coatings polymer matrices can be used;

(4) Tailored capping systems can be designed to minimize the early release of the corrosion inhibitors from MSN and widely modulate the release kinetics;

(5) Engineered MSN-based systems can be designed to promote the stimuli-responsive release of the corrosion inhibitors under selected conditions (such as $\mathrm{pH}$ variations);

(6) MSN can protect the corrosion inhibitors from degradation, such as UV-induced or high temperature-induced degradation;

(7) MSN can be properly functionalized to promote their compatibility (both enhancing dispersion and interfacial interactions) with organic coatings, improving functional and structural (e.g. mechanical, adhesion, indentation resistance) properties;

(8) Finally, when engineered MSN are effectively embedded in protective coatings, they contribute to maximize both the anticorrosive properties through active (e.g. stimuliresponsive release of anticorrosive agents) and passive mechanisms (e.g. hindering the movement of aggressive species).

To confirm the above points, in this work, the main approaches for the synthesis of MSN as nanocarriers of corrosion inhibitors with tailored textural properties, for the design of different loading/release strategies, and for the use of MSN to realize advanced organic coatings are reviewed and compared. Moreover, results of the application of the obtained smart anticorrosive coatings for the protection of different metal and alloy substrates used in civil and industrial buildings and infrastructures, transportation, aeronautics and cultural heritage are reported and critically discussed.

\section{Mesoporous silica nanoparticles (MSN)}

MSN represent a versatile and inexpensive kind of nanoreservoir with excellent chemical stability, biocompatibility, controllable pore diameter, easy surface functionalization, high surface area and pore volume. ${ }^{36-41}$

MSN can be synthetized by a modified Stober process, ${ }^{42}$ by hydrolysis and condensation of silica precursors. ${ }^{43}$ Usually tetraethylorthosilicate (TEOS) or tetramethylorthosilicate $(\mathrm{TMOS})^{44}$ are used, but also other precursors are often reported. For instance, 3-mercaptopropyltrimethoxysilane (MPTMS) has been used by Sivanandini et al., ${ }^{45}$ demonstrating the improved efficiency of this precursor for the MSN synthesis, able to reduce the particles aggregation and improving their geometric uniformity. Moreover, surfactant, micelles forming materials, polymers or other dopants ${ }^{46-49}$ are added to the selected precursors.

In particular, the most used surfactant is cetyltrimethylammonium bromide $(\mathrm{CTAB})^{50-61}$ although other salts are often exploited, such as hexadecyltrimethylammonium p-toluenesulfonate (CTAT), cetyltrimethylammonium chloride $(\mathrm{CTAC})^{62}$ and dodecyltrimethylammonium bromide $\left(\mathrm{C}_{12} \mathrm{TMABr}^{\mathrm{T}}{ }^{44,63,64}\right.$

In the mesoporous silica nanoparticles growth, by selecting adequately the $\mathrm{pH}$, the condensation of silicon is enhanced with respect to the Stober process, promoting the formation of $\mathrm{Si}-\mathrm{O}-\mathrm{Si}$ bonds, instead of $\mathrm{Si}-\mathrm{OH} .{ }^{65}$ Then, pores are formed with the template removal in the nanoparticle structure through calcination or by solvent extraction (see Fig. 1).

Many factors concur to determine the MSN porous structure, such as the type of surfactant and the reaction conditions, allowing to control the nanoparticles pores size in the whole range of the mesopores, and, in some cases, also in the

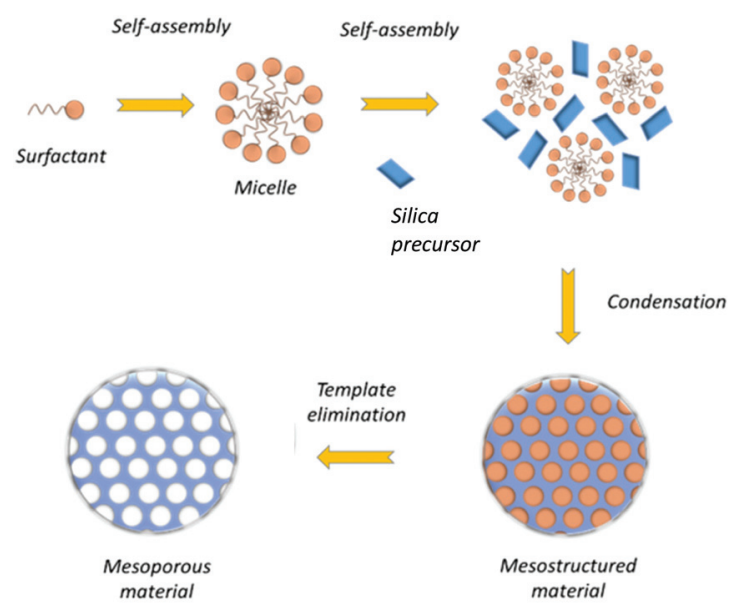

Fig. 1 Schematic representation of the MSN synthesis. 
a)

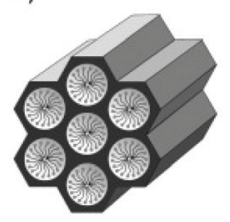

b)

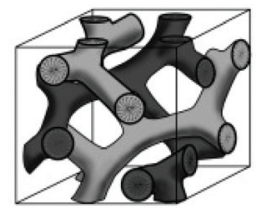

c)

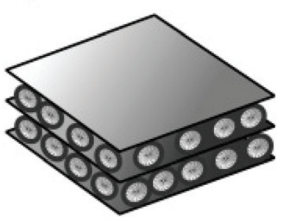

Fig. 2 Hexagonal, cubic and lamellar mesostructures of MCM-41 (a), MCM-48 (b) and MCM-50 (c), respectively. Reprinted with permission from ref. 78. Copyright 2006 John Wiley and sons.

range of the micropores, until the lower limit of about $0.1 \mathrm{~nm}^{66}$

The MSN may have different mesostructures (Fig. 2), some of them take the name from their developers, and are distinguished in:

- Hexagonal, such as the "Mobil Composition of Matter number 41" (MCM-41), ${ }^{52,57}$ "Santa Barbara Amorphous type number 15" (SBA-15) $)^{67-69}$ or "Folded Sheets Mesoporous material number 16" (FSM-16); ${ }^{70}$

- Cubic, such as MCM-48; ${ }^{71,72}$

- Lamellar, such as MCM-50; ${ }^{73}$

- Other random structures, ${ }^{74}$ such as the "Technische Universiteit Delft number 1" (TUD-1), ${ }^{75}$ the "Hiroshima Mesoporous Material number 33" (HMM-33) ${ }^{76}$ and the "Michigan State University type number 1 " (MSU-1). ${ }^{77}$

In Table 1 the different mesostructures and textural properties of the above mentioned MSN are summarized.

Among the different types of pores morphology, Zhang et $a{ }^{24}{ }^{24}$ demonstrated that, by varying the $\mathrm{pH}$ of the reaction mixture, so-called stellate, raspberry or worm-like structures can be also obtained (Fig. 3).

Moreover, MSN with a hollow structure (HMSN) can be obtained with the use of proper templates. ${ }^{79}$ HMSN can display significantly higher pore volumes than MSN, and for this reason they are very attractive for a wide range of applications. $^{79}$ For their synthesis, the templates employed are usually classified in "hard" templates, such as polymeric materials, ${ }^{80-82}$ silica, ${ }^{83}$ carbon $^{84}$ or inorganic salts ${ }^{85}$ spheres, or "soft" templates, such as gas bubbles, ${ }^{86}$ surfactant

Table 1 Mesostructures and textural properties of MSN

\begin{tabular}{lllll}
\hline $\begin{array}{l}\text { MSN } \\
\text { structure }\end{array}$ & $\begin{array}{l}\text { MSN } \\
\text { name }\end{array}$ & Ref. & $\begin{array}{l}\text { Surface area } \\
\left(\mathrm{m}^{2} \mathrm{~g}^{-1}\right)\end{array}$ & $\begin{array}{l}\text { Pore diameter } \\
(\mathrm{nm})\end{array}$ \\
\hline Hexagonal & MCM-41 & 52 & 1016 & 3.77 \\
& SBA-15 & 67 & $\begin{array}{l}\text { Not reported } \\
789\end{array}$ & $\begin{array}{l}<5 \\
\end{array}$ \\
& & 68 & $550-600$ & $6-10$ \\
& & 69 & 609 & 8 \\
Cubic & MCM-48 & 71 & $994-1258$ & $1.6-4.5$ \\
& & 72 & $1331-1464$ & $3.2-3.6$ \\
Lamellar & MCM-50 & 73 & 1222 & 5.6 \\
Random & TUD-1 & 75 & 453 & 4.9 \\
& HMM-33 & 76 & 600 & 5 \\
& MSU-1 & 77 & 891 & 2.5
\end{tabular}

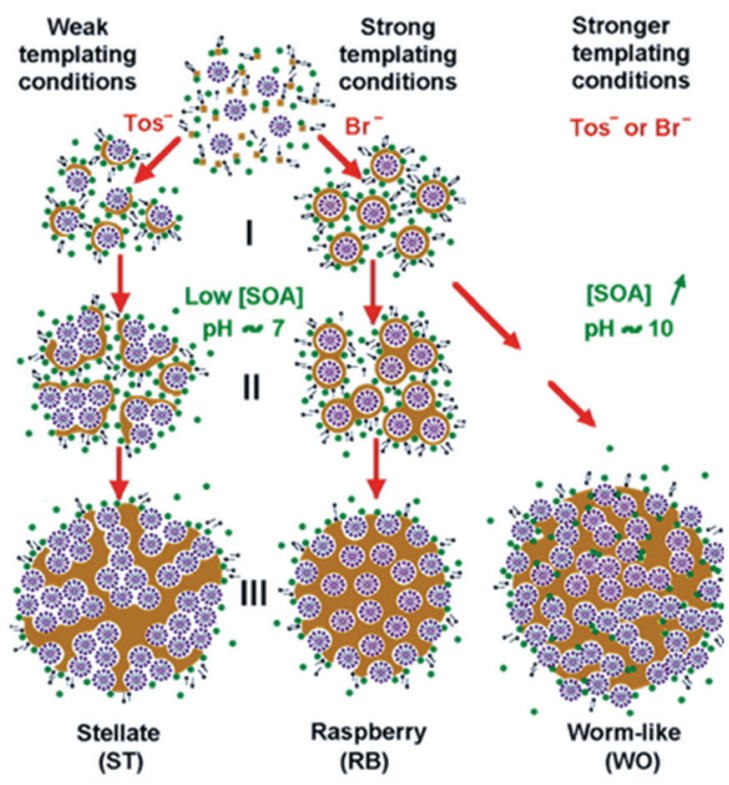

Fig. 3 Reaction conditions for stellate, raspberry and worm-like MSN porous structures obtained at different small organic amines (SOA) concentrations ( $\mathrm{pH} \approx 7$ or 10 ) and with different surfactants (CTAT and CTAB). Reprinted with permission from ref. 24. Copyright 2013 American Chemical Society.

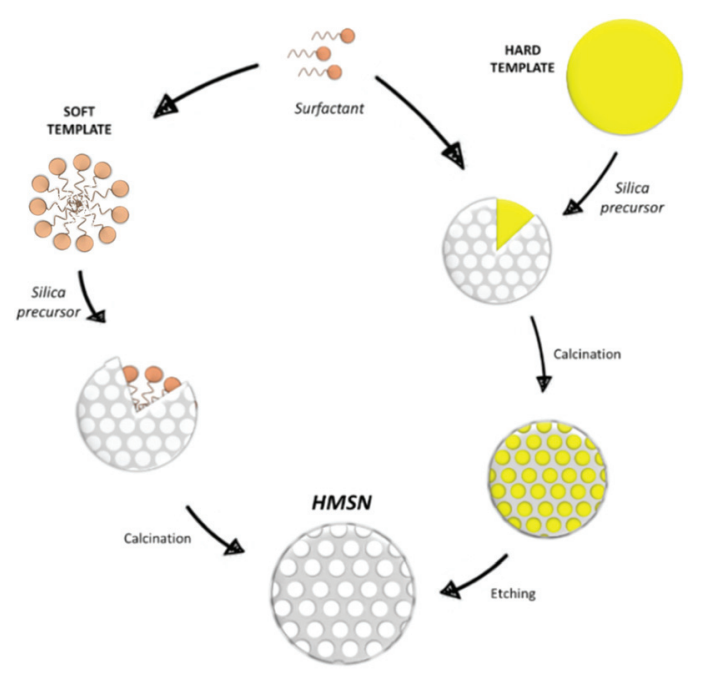

Fig. 4 Hard and soft templating in HMSN synthesis.

micelles, ${ }^{87-90}$ vesicle template ${ }^{91-93}$ or emulsion or aerosol droplets $^{94-99}$ (Fig. 4).

When using surfactant micelles, the difference between HMSN and MSN syntheses mainly consists in the amount of surfactant employed: increasing the surfactant/silica precursor ratio promotes the formation of hollow structures. ${ }^{88}$ In the hard template case, a great control in particles growth is guaranteed and an etching treatment is needed to remove the template. $^{100}$

A drawback of this process is that, in some cases, it can cause partial collapse of the hollow structure. ${ }^{101}$ On the other 
hand, soft templates can be removed by heating, calcination or solvent extraction but, in these cases, the obtainment of homogeneous nanoparticles is more challenging, due to the low rigidity of the template. ${ }^{79}$ Finally, a soft-hard template approach, based on the simultaneous presence of a soft and a hard template, can be also pursued for the HMSN synthesis. For example, Zhang et al. ${ }^{102}$ exploited the combination of carbon nanospheres and CTAB, while Zhu et al. ${ }^{103}$ and Chenan et al. ${ }^{104}$ used polyvinylpirrolidone (PVP) and CTAT or CTAB.

\section{Loading of corrosion inhibitors into MSN and its effectiveness}

In order to employ MSN as smart nanocontainers, several approaches have been designed to maximize the loading of the active molecules while ensuring that their release mainly occur in response to external stimuli. Main strategies applied to realize the corrosion inhibitors loading are presented and discussed in the following sections with a specific focus on pristine MSN, surface modified MSN and organically coated MSN.

\section{Pristine MSN}

One of the most effective approach to load corrosion inhibitors into MSN consists in mixing the nanoparticles with a corrosion inhibitor solution under reduced pressure. The reduced pressure promotes the penetration and physical adsorption of the active molecule into the MSN pores. Then, under proper temperature and pressure conditions, the solvent is evaporated, leaving the corrosion inhibitor into the pores, ${ }^{105,106,107}$ Active molecules have also been adsorbed into MSN from solution without vacuum application, ${ }^{62,108}$ even if this simplified strategy allows only to load limited amount of corrosion inhibitor, since it is not possible to limit its premature release during the loading procedure. ${ }^{19}$ In Fig. 5a a typical active molecule loading into silica mesopores is schematized.
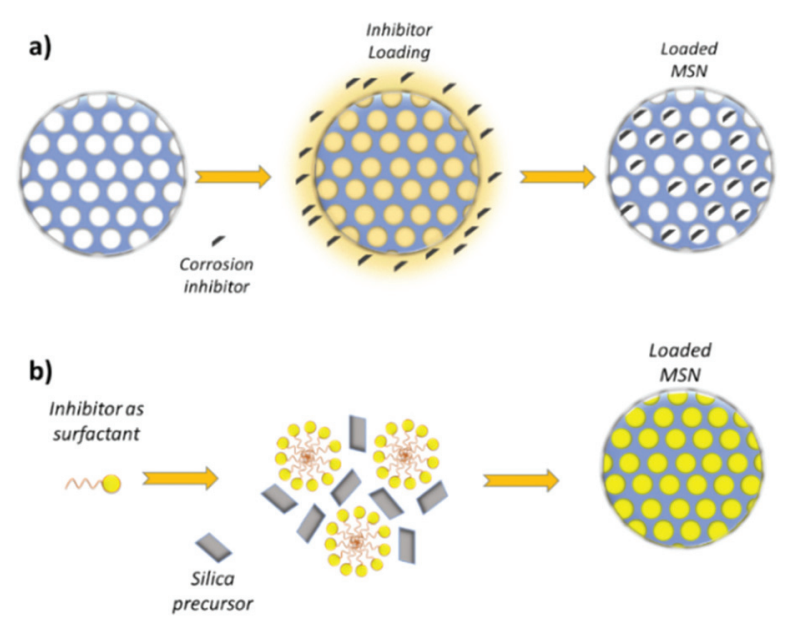

Fig. 5 Corrosion inhibitor loading into the pores (a) and one-step MSN synthesis and drug loading, wherein the surfactant also acts as the loaded active molecule (b).
Among the investigated corrosion inhibitors loaded into mesostructures, several works focused on benzotriazole (BTA), which is a very effective organic inhibitor with high solubility in water and in organic solvents (e.g. acetone) $)^{105,109-112}$ and mercaptobenzothiazole (MBT), another organic inhibitor insoluble in water and soluble in organic solvent such as ethanol, acetone and ether. ${ }^{104,108,113-115}$ Other organic inhibitors are 8-hydroxyquinoline (8-HQ) ${ }^{106} \mathrm{PVP}^{116}$ hydroxybenzotriazole (HOBt), ${ }^{62}$ sulfamethazine $^{61}$ and dodecylamine. ${ }^{117}$ Some researchers have also developed systems with inorganic corrosion inhibitors. Zea et al. ${ }^{63}$ proposed the loading of sodium phosphomolybdate $\left(\mathrm{Na}_{3}\left[\mathrm{P}\left(\mathrm{Mo}_{3} \mathrm{O}_{10}\right)_{4}\right]\right)$ in MSN pores as an environment friendly compound. Other inorganics were also exploited, such a cerium nitrate hexahydrate (Ce $\left.\left(\mathrm{NO}_{3}\right)_{3} \cdot 6 \mathrm{H}_{2} \mathrm{O}\right)$, proposed by Noiville et al. ${ }^{118}$

With another approach, schematized in Fig. 5b, researchers also investigated the possibility to synthesize the MSN and load the corrosion inhibitor in a one-step process. Maia et al. ${ }^{51}$ first mixed MBT and CTAB, then added TEOS to the mixture and promoted the synthesis of MSN, encapsulating MBT into the synthesized mesopores of the silica nanoparticles. Xu et $a{ }^{119}$ followed the same procedure, studying the effect of BTA loading. Jiang et al. ${ }^{120}$ mixed TEOS, CTAB and cerium chloride $\left(\mathrm{CeCl}_{3}\right)$ and synthetized MSN through aerosol assisted evaporation-induced self-assembling (EISA).

Although a single step synthesis and corrosion inhibitor loading is very attractive, the formation of mesopores in presence of corrosion inhibitors could lead to the obtainment of an imperfect porous structure. ${ }^{120}$

In Table 2 the various loading strategies presented in this section are summarized. As shown, the amount of corrosion inhibitor loaded varies in a wide range, approximately from 10 to more than $80 \mathrm{wt} \%$ with respect to the weight of MSN. In fact, the amount of loaded corrosion inhibitor depends on the pore size and volume of the nanoparticles and on the corrosion inhibitor molecular dimension. In particular, HMSN have a great potential in active molecules loading, since they show an increased pore volume that allows the loading of higher amount of corrosion inhibitor. In this way, Chenan et al. ${ }^{104}$ loaded about $72 \mathrm{wt} \%$ of MBT into HMSN. In general, then, very high amount of loadings in MSN may be due to surface excess adsorption of molecules in multilayer coverage.

The strategy based on the simple corrosion inhibitor loading is not often followed, due to the difficulty in holding the loaded corrosion inhibitor into the nanoparticle. ${ }^{121}$ Therefore, researchers developed several "stopping systems", based on nanoparticles functionalization with functional groups somehow bound to the corrosion inhibitors or external coatings surrounding the MSN. In most of these cases, the corrosion inhibitor release can be modulated and activated in response to an external trigger.

\section{Surface modified MSN}

The development of surface modified MSN is a widely exploited approach to optimize the loading and modulate the corrosion inhibitor release, and it may interest the internal 
Table 2 Pristine MSN loaded with corrosion inhibitors

\begin{tabular}{llll}
\hline Corrosion inhibitor loading technique & Ref. & Loaded corrosion inhibitor molecule & Corrosion inhibitor loading content \\
\hline MSN synthesis and corrosion inhibitor & 62 & Hydroxybenzotriazole & $40 \mathrm{wt} \%$ \\
loading without reduced pressure & 108 & Mercaptobenzothiazole & $35 \mathrm{wt} \%$ \\
MSN synthesis and reduced pressure corrosion & 61 & Sulfamethazine & Not reported \\
inhibitor loading & 63 & Sodium phosphomolybdate & $72 \mathrm{wt} \%$ \\
& 104 & Mercaptobenzothiazole & $20 \mathrm{wt} \%$ \\
& 113 & & $20 \mathrm{wt} \%$ \\
& 114 & & $83.7 \mathrm{wt} \%$ \\
& 115 & & $17 \mathrm{wt} \%$ \\
& 105 & Benzotriazole & $77 \mathrm{wt} \%$ \\
One-step MSN synthesis and corrosion inhibitor loading & 106 & 8-Hydroxyquinoline & Not reported \\
& 118 & Cerium nitrate hexahydrate & $10 \mathrm{wt} \%$ \\
& 119 & Bercaptobenzothiazole & $16 \mathrm{wt} \%$ \\
& 120 & Cerium chloride & Not reported
\end{tabular}

surface of the pores and/or their edges. The MSN decoration can be operated during the MSN synthesis ${ }^{122,123}$ or after the synthesis $^{52,54-56,58-60,69,124}$ and, in some cases, after the corrosion inhibitor loading or grafting..$^{57,125}$

Surface modification is generally operated through organosilanes, that can easily react with the MSN surface. The most used silanes have $-\mathrm{NH}_{2}$ functionality, in order to impart to silica a basic character and improve its reactivity towards further functionalization. 3-Aminopropyltriethoxysilane (APTES), ${ }^{55,67,124}$ (1-(2-aminoethyl)-3-aminopropyltriethoxysilane) (AEAPTMS) ${ }^{54,56,58-60,122}$ and 3-trimethoxysylispropylamine (TMSPA) ${ }^{52}$ are among the most used amino precursors. Yeganeh et al., in their works, induced the reaction between amino-functionalized MSN and $\mathrm{Fe}^{3+}$ or $\mathrm{Al}^{3+}$, by reacting the particles with $\mathrm{FeCl}_{3}{ }^{56,58-60,122}$ and $\mathrm{AlCl}_{3},{ }^{54}$ respectively. The presence of the intermediate metal cations $\mathrm{Fe}^{3+}$ or $\mathrm{Al}^{3+}$ was then exploited by several research groups to load the nanoparticles with anionic corrosion inhibitors, such as molybdates ${ }^{54,58-60,122}$ or fluorides ${ }^{56,124}$ (Fig. 6).

Kermannezhad et $a .^{52}$ followed similar approaches, using TMSPA to graft 2-mercaptobenzoxazole (MBA). Ashrafi-Shahri et $a l .{ }^{55}$ functionalized MSN with APTES and, in a second step, with $\mathrm{FeCl}_{3}$, in order to graft the corrosion inhibitor Eriochrom Black $\mathrm{T}$ (EBT, $\mathrm{C}_{20} \mathrm{H}_{12} \mathrm{~N}_{3} \mathrm{O}_{7} \mathrm{SNa}$ ). Amini et al. ${ }^{69}$ functionalized MSN with piperazine, in order to improve the MBT capability to load the mesopores.

Another highly exploited functionality is based on - $\mathrm{SH}$ groups, which induce an acid character to the nanoparticles, as in the case of MSN functionalized with MPTMS. In this way, Alipour et al. ${ }^{57}$ exploited MPTMS to improve the efficiency of MSN impregnated with molybdate as a corrosion inhibitor. The authors showed that protective compounds are formed after release of molybdate from mesoporous silica, while the functionalization with MPTMS promoted the self-healing property of the anticorrosive coating by reducing the coating porosity and by increasing the coating hydrophobicity and its compatibility with the metal substrate.

Promoting the hydrophobization by using different silanes was an approach adopted in several works. In order to improve the dispersion of BTA loaded MSN into a polyester-resin based

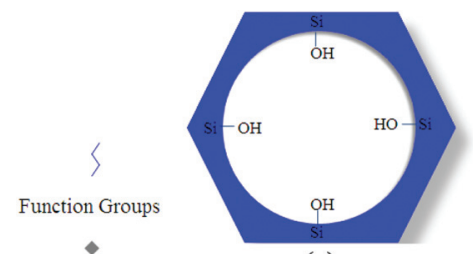

(a)

(c)

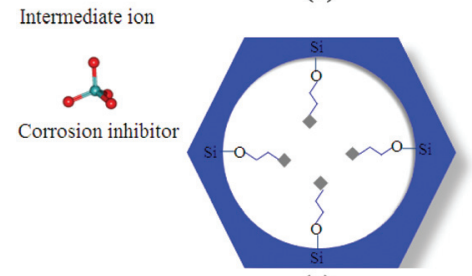

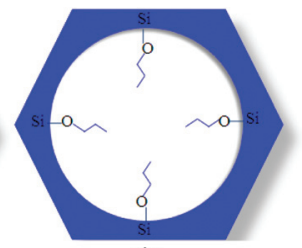

(b)

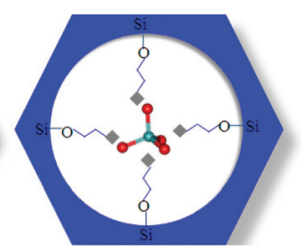

(d)
Fig. 6 The three step mechanism exploited to load anionic corrosion inhibitors into MSN: (a) starting MSN; (b) functionalized MSN (treated for instance with amino silanes); (c) amino-functionalized MSN treated with metal cations (such as $\mathrm{Fe}^{3+}$ or $\mathrm{Al}^{3+}$ ); (d) anionic corrosion inhibitors (such as molybdates or fluorides) "entrapped" into MSN pores by coordination chemistry. Reprinted from ref. 58. Copyright 2014, with permission from Elsevier.

coating, Hollamby et al. $^{123}$ functionalized MSN with octyltriethoxysilane (OTES), while Zhao et al. ${ }^{125}$ functionalized BTA loaded MSN with dodecyltrimethoxysilane (DTMS) to improve the hydrophobicity of a mesoporous film onto an aluminium alloy substrate.

On the other hand, other MSN functionalizations were pursued with the aim of creating a responsive shell outside the nanoparticles. External stimuli, such as $\mathrm{pH}$ changes, redox reactions, temperature gradient and light irradiation, can modify the external shell and induce the corrosion inhibitor release. These shells act as switches, which modify their location, shape or structure in response to stimuli. ${ }^{126}$ These switches can have varying complexity. For instance, they can be obtained by molecules directly grafted to MSN or by realizing complex systems, applying non-covalently bonded or mechanically interlocked shells. ${ }^{126}$ 
Chen et al. proposed a one-molecule-grafted approach: during a typical HMSN synthesis, they added 4-phenylazoaniline (4-PhAA), an azobenzene, and also isocyanatopropyltriethoxysilane (ICPES) to graft azobenzene onto HMSN and, then loaded BTA into the nanopores. ${ }^{5}$ This switch is ultraviolet (UV) activated, exploiting the cis/trans isomerization of azobenzene, ${ }^{127}$ which modifies the azobenzene shell onto MSN, thus inducing the BTA release. ${ }^{47}$

Sun et al. ${ }^{128}$ demonstrated the redox-responsive character of MBT loaded HMSN, capped with zinc oxide ( $\mathrm{ZnO})$ through APTES and dithiodipropionic acid (DTPA).

More complex structures were realized by Fu's group, who largely investigated how to functionalize MSN in order to create a pH responsive nanovalve outside the nanoparticle. ${ }^{129-135}$ This mechanism is based on the noncovalent interaction between the installed macrocycle and the external surface long chain molecule. ${ }^{130}$ Their research focused on cucurbit $[n]$ uril $(\mathrm{CB}[n])$, macrocyclic molecules used by the authors as a cage. ${ }^{129-132}$ In particular, they used $\mathrm{CB}[7]^{129}$ and $\mathrm{CB}[6]^{130-132} \mathrm{CB}[7]$, hexanediamine (HDA) and ferrocene dicarboxylic acid (FCDCA) composed a pseudorotaxanes grafted outside the HMSN (through chloromethyltriethoxysilane, CMTES), loaded with caffeine, used as corrosion inhibitor. ${ }^{129}$ Instead, $\mathrm{CB}[6]$ was used in interaction with butanediamine (BDA) and chloropropyltriethoxysilane (CPTES) ${ }^{130}$ or CMTES. ${ }^{131}$ Moreover, they developed a similar system realized by the simultaneous use of HDA and 1,6-bis (pyridinium)hexane (BPH) as two recognition sites onto HMSN, capped with $\mathrm{CB}[6]{ }^{132}$ Other supramolecular nanovalves are based on pillararenes (WPs) ${ }^{133,134}$ and cyclodextrin (CDs). ${ }^{131,136}$ In these systems, the corrosion inhibitor used was BTA, ${ }^{130-132}$ 8-HQ, ${ }^{134}$ 2-hydroxy-4-methoxy-acetophenone $(\mathrm{HMAP})^{133}$ and $p$-coumaric acid (CA). ${ }^{136}$

Furthermore, the corrosion inhibitor can be exploited to realize an external blocking system after its loading into the mesopores. This approach is based on the interaction between the corrosion inhibitor and an external compound, assembling a complex outside the nanopores, which modulate the release rate. Abdullayev et al. ${ }^{137-139}$ tailored the controlled BTA release from other inorganic carriers (halloysite nanotubes), through its reaction with copper ions, forming a $\mathrm{Cu}-$ BTA complex. They exploited the properties of the Cu-BTA complex whose water solubility is $\mathrm{pH}$ responsive, obtaining the release of BTA with the decrease of $\mathrm{pH}$. $\mathrm{Cu}-\mathrm{BTA}$ complexes were also exploited in MSN by Zheng et al. ${ }^{140}$ and Castaldo et $a .^{141}$ for self-healing and anticorrosive applications (see Fig. 7).

In Table 3, the results obtained by applying the functionalization approaches described in this section are summarized. As shown, also in this case the loading efficiency ranges from values lower than $1 \mathrm{wt} \%$ up to about $25 \mathrm{wt} \%$. To be noted is that, in general, these systems show a lower loading of corrosion inhibitors with respect to the pristine MSN summarized in Table 2. Indeed, a functionalization of the MSN may reduce the surface adsorption sites and/or the pore volume of the nanoparticles, thus reducing the MSN loading capability.

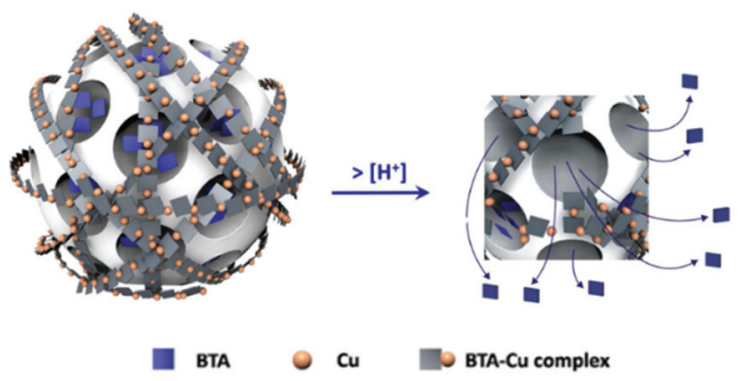

Fig. 7 Scheme of the BTA release in acid solution. Reproduced from ref. 141 Copyright (c) 2020, Elsevier Masson SAS. All rights reserved.

Moreover, the application of blocking systems may induce the release of part of the loaded active molecules.

\section{Organically coated MSN}

Another approach aimed to modulate the corrosion inhibitors release rate is based on building stimuli responsive coatings around the nanoparticles loaded with the corrosion inhibitors.

These strategies aim to maximize the exploitation of the inner porosity of the nanoparticles for the active molecules loading, developing a stimuli responsive release system on the external surface of the nanoparticles.

For example, layer-by-layer (LbL) deposition of polyelectrolytes is a largely used approach. ${ }^{68,142-148}$ Skorb et al. ${ }^{143}$ developed a pH sensitive polyelectrolyte shell made by a deposition of alternate layers of polyethyleneimine (PEI) and poly(sodium 4-styrenesulfonate) (PSS), enwrapping the corrosion inhibitor 2-(benzothiazol-2-ylsulfanyl)-succinic acid (BYS) into the MSN pores. They also developed a laser-driven release of BTA from MSN coated with the same polyelectrolyte shell. ${ }^{142}$ Shi et al. ${ }^{68}$ and Siva $e t ~ a l .{ }^{144}$ realized a PEI/PSS polyelectrolyte layer, encapsulating the corrosion inhibitor 8-HQ and polyaspartic acid (PAA). Zea et al., ${ }^{146-148}$ deposited poly(diallyldimethylammonium chloride) (PDDA) pH-responsive polyelectrolyte layers onto HMSN loaded with sodium phosphomolybdate, using sodium chloride $(\mathrm{NaCl})$ to improve the efficiency in the deposition of the polyelectrolyte (Fig. 8).

In details, $\mathrm{NaCl}$ enhances the ionic strength, and allows to overcome the electrostatic barrier formed between the deposited polyelectrolyte layers and the bulk molecules in the polymeric solution, and therefore to deposit a higher number of polyelectrolyte layers.

Grigoriev et $a l .{ }^{145}$ developed a system based on MSN loaded with BTA and covered with a polyelectrolyte layer which was in turn complexed with the corrosion inhibitor (BTA), combining a double anti-corrosive effect. The complete structure outside the MSN consisted of PEI/PSS layers, covered with further PSS/ BTA complex layers. PEI was also used by Wen et al. ${ }^{149}$ which used it to enwrap BTA loaded MSN, previously functionalized with APTES.

The combination of active and passive corrosion protection is a very attractive goal, especially when the corrosion inhibitors nanocarriers are designed for being included into protec- 
Table 3 Surface modified MSN loaded with corrosion inhibitors

\begin{tabular}{|c|c|c|c|c|c|}
\hline $\begin{array}{l}\text { Functionalization } \\
\text { step }\end{array}$ & $\begin{array}{l}\text { External } \\
\text { nanovalve } \\
(\mathrm{X})\end{array}$ & Ref. & $\begin{array}{l}\text { Silane modification and other functionalities } \\
\text { between MSN and corrosion inhibitor }\end{array}$ & Corrosion inhibitor & $\begin{array}{l}\text { Corrosion } \\
\text { inhibitor } \\
\text { loading }\end{array}$ \\
\hline \multirow[t]{3}{*}{$\begin{array}{l}\text { During MSN } \\
\text { synthesis }\end{array}$} & \multirow[t]{12}{*}{$\mathbf{X}$} & 5 & $\begin{array}{l}\text { Isocyanatopropyltriethoxysilane, } \\
\text { phenylazoaniline }\end{array}$ & \multirow[t]{2}{*}{ Benzotriazole } & $25.2 \mathrm{wt} \%$ \\
\hline & & 123 & Octyltriethoxysilane & & $1 \mathrm{wt} \%$ \\
\hline & & 123 & Aminoethylaminopropyltriethoxysilane, $\mathrm{FeCl}_{3}$ & Sodium molybdate & Not reported \\
\hline \multirow{20}{*}{$\begin{array}{l}\text { After MSN synthesis } \\
\text { and before } \\
\text { corrosion } \\
\text { inhibitor loading }\end{array}$} & & 52 & Trimethoxysylispropylamine & Mercapto-benzoxazole & 25 wt $\%$ \\
\hline & & 54 & Aminoethylaminopropyltriethoxysilane, $\mathrm{AlCl}_{3}$ & \multirow[t]{4}{*}{ Sodium molybdate } & $18 \mathrm{wt} \%$ \\
\hline & & 58 & Aminoethylaminopropyltriethoxysilane, $\mathrm{FeCl}_{3}$ & & $18 w t \%$ \\
\hline & & 59 & & & Not reported \\
\hline & & 60 & & & Not reported \\
\hline & & 56 & & \multirow[t]{2}{*}{$\mathrm{NaF}$} & Not reported \\
\hline & & 124 & \multirow{2}{*}{ Aminopropyltriethoxysilane, $\mathrm{FeCl}_{3}$} & & Not reported \\
\hline & & 55 & & Eriochrom Black T & Not reported \\
\hline & & 69 & Piperazine & \multirow[t]{2}{*}{ Mercapto-benzo-thiazole } & 13 wt $\%$ \\
\hline & $\mathbf{X}$ & 128 & $\begin{array}{l}\text { Aminopropyltriethoxysilane, dithiodipropionic } \\
\text { acid and ZnO }\end{array}$ & & $4.1 \mathrm{wt} \%$ \\
\hline & $\mathbf{X}$ & 129 & $\begin{array}{l}\text { Chloromethyltriethoxysilane, hexanediamine, } \\
\text { ferrocene dicarboxylic acid and cucurbituril[7] }\end{array}$ & Caffeine & $20.2 \mathrm{wt} \%$ \\
\hline & $\mathbf{X}$ & 130 & $\begin{array}{l}\text { Chloropropyl-triethoxysilane, butanediamine and } \\
\text { cucurbituril[6] }\end{array}$ & \multirow[t]{3}{*}{ Benzotriazole } & $64 \mathrm{wt} \%$ \\
\hline & $\mathbf{X}$ & 131 & $\begin{array}{l}\text { Octadecyltrimethoxysilane, chloromethyltriethoxysilane } \\
\text { and phenylaminomethyltriethoxysilane, butanediamine, } \\
\text { cucurbituril[6] and } \alpha \text {-cyclodextrin }\end{array}$ & & $11.3 \mathrm{wt} \%$ \\
\hline & $\mathbf{X}$ & 132 & $\begin{array}{l}\text { Aminopropyltriethoxysilane, hexanediamine, } \\
\text { bispyridiniumhexane and cucurbituril[6] }\end{array}$ & & $\begin{array}{l}\text { About } 11.6 \mathrm{wt} \% \\
\text { including the } \\
\text { capping } \\
\text { agent }\end{array}$ \\
\hline & $\mathbf{X}$ & 133 & $\begin{array}{l}\text { Aminopropyltriethoxysilane, ammonium } \\
\text { carboxylated pillar[5]arane }\end{array}$ & $\begin{array}{l}\text { Hydroxy-methoxy-aceto- } \\
\text { phenone }\end{array}$ & $12.4 \mathrm{wt} \%$ \\
\hline & $\mathbf{X}$ & 134 & $\begin{array}{l}\text { Mercaptopropyltrimethoxysilane, ammonium } \\
\text { carboxylated pillar[5] arane, } \mathrm{Fe}_{3} \mathrm{O}_{4}\end{array}$ & Hydroxyquinoline & $0.72 \mathrm{wt} \%$ \\
\hline & \multirow[t]{4}{*}{$\mathbf{X}$} & 136 & $\begin{array}{l}\text { Aminopropyltriethoxysilane, } \\
\text { ferrocenylmethyltriazolylmethyl-heptakisdeoxyiodo- } \\
\beta \text {-cyclodextrin }\end{array}$ & Coumaric acid & $15 \mathrm{wt} \%$ \\
\hline & & \multirow[t]{3}{*}{140} & Aminopropyltriethoxysilane, $\mathrm{CuSO}_{4}$ & \multirow[t]{3}{*}{ Benzotriazole } & $\begin{array}{l}7.3 \text { wt\% (by TGA); } \\
6.6 \text { wt\% (by UV) }\end{array}$ \\
\hline & & & Trimethoxysilylpropylethylenediamine, $\mathrm{CuSO}_{4}$ & & $\begin{array}{l}8.9 \text { wt } \% \text { (by TGA); } \\
8.5 \% \text { wt } \% \text { (by UV) }\end{array}$ \\
\hline & & & Trimethoxysilylpropyldiethylen-triamine, $\mathrm{CuSO}_{4}$ & & $\begin{array}{l}8.6 \text { wt } \% \text { (by TGA); } \\
7 \text { wt\% (by UV) }\end{array}$ \\
\hline \multirow{3}{*}{$\begin{array}{l}\text { After MSN } \\
\text { synthesis } \\
\text { and corrosion } \\
\text { inhibitor loading }\end{array}$} & & 57 & Mercaptopropyltrimethoxysilane & Sodium molybdate & $10 \mathrm{wt} \%$ \\
\hline & & 140 & $\mathrm{CuSO}_{4}$ & \multirow[t]{2}{*}{ Benzotriazole } & $\begin{array}{l}10.3 \text { wt } \% \text { (by } \\
\text { TGA); } \\
9.2 \text { wt } \% \text { (by UV) }\end{array}$ \\
\hline & & 141 & & & $20 \%$ \\
\hline
\end{tabular}

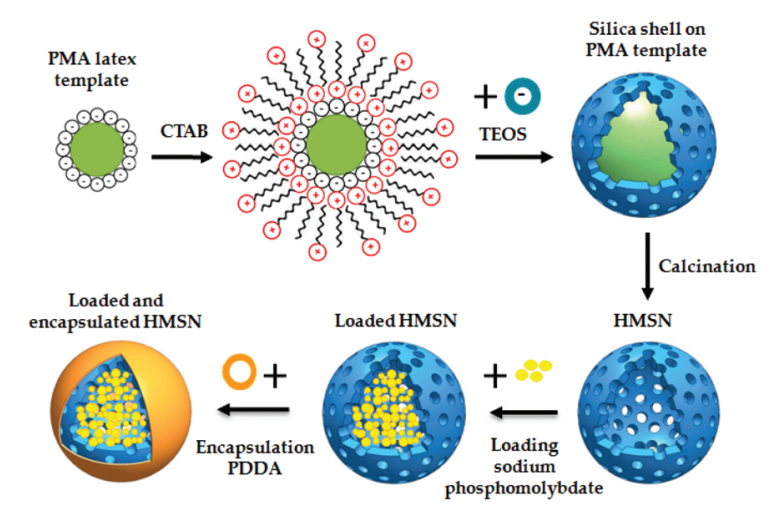

Fig. 8 HMSN synthesis, through hard polystyrene methylacrilic (PMA) template, HMSN loading with sodium phosphomolybdate and polyelectrolyte PDDA coating. Reproduced from Zea et al. ${ }^{146}$ tive coatings for metals. For this reason, the possibility to synthesize nanocarriers able to intrinsically create passivating films onto metal surface is very interesting. Wang et al. ${ }^{150}$ realized BTA loaded MSN modified with a polyaniline (PANI) polyelectrolyte external layer, wherein PANI acts as passive corrosion protection agent. A hard template silica nanoparticle was functionalized with PVP in order to graft aniline, which was polymerized onto the surface of PVP-modified silica. Then, the PANI-modified silica nanoparticles were etched with sodium hydroxide and phosphoric acid and then calcined, obtaining a void PANI-modified silica nanoparticle, thanks to the "protective" effect of PVP that disallowed the complete etching of the silica, promoting the mesoporous structure formation. Finally, BTA was loaded into the obtained system, exploiting its high capability to penetrate into PANI: ${ }^{151}$ the 
Table 4 Coated MSN loaded with corrosion inhibitors

\begin{tabular}{|c|c|c|c|c|c|}
\hline Coating step & Ref. & Type of coating & Coating structure & Corrosion inhibitor & $\begin{array}{l}\text { Corrosion } \\
\text { inhibitor loading } \\
\text { content }\end{array}$ \\
\hline \multirow{11}{*}{$\begin{array}{l}\text { Before corrosion } \\
\text { inhibitor loading } \\
\text { After corrosion } \\
\text { inhibitor loading }\end{array}$} & 150 & $\begin{array}{l}\text { Polyelectrolyte } \\
\text { layers }\end{array}$ & Polyvinylpyrrolidone and polyaniline & Benzotriazole & $26.9 \mathrm{wt} \%$ \\
\hline & 68 & & Polyethyleneimine/polystyrene sulphonate & Hydroxyquinoline & $8 \mathrm{wt} \%$ \\
\hline & 142 & & & $\begin{array}{l}\text { Benzothiazolyl- } \\
\text { sulfanylsuccinic acid }\end{array}$ & $\approx 8.5 \mathrm{wt} \%$ \\
\hline & 143 & & & Benzotriazole & 7.5 wt $\%$ \\
\hline & 144 & & & Polyaspartic acid & Not reported \\
\hline & 145 & & $\begin{array}{l}\text { Polyethyleneimine/polystyrene sulphonate }+ \\
\text { polystyrene sulphonate/benzotriazole }\end{array}$ & Benzotriazole & \\
\hline & 146 & & Poly(diallyldimethyl-ammonium chloride) & Sodium & \\
\hline & 147 & & & phosphomolybate & \\
\hline & 148 & & & & \\
\hline & 149 & & $\begin{array}{l}\text { Aminopropyltriethoxysilane and } \\
\text { polyethyleneimine }\end{array}$ & Benzotriazole & $10.09 \mathrm{wt} \%$ \\
\hline & 152 & $\begin{array}{l}\text { Self-assembled } \\
\text { external layers }\end{array}$ & Tannic acid-Fe complex & Benzotriazole & Not reported \\
\hline
\end{tabular}

peculiarity of this process is that BTA loading is performed after the obtainment of the PANI external layer.

Finally, with another approach, Qian et al. ${ }^{152}$ reported a pH-responsive capping layer, based on tannic acid (TA)- $\mathrm{Fe}^{3+}$ complexes, able to coat BTA loaded MSN and act as effective capping agents for the loaded BTA. With the proposed approach, the authors exploited the $\mathrm{pH}$ dependent stability of the $\mathrm{TA}-\mathrm{Fe}^{3+}$ complex and the affinity of the complex to the MSN substrates, without any further MSN surface functionalization, avoiding the polyelectrolyte layers deposition.

In Table 4 the results obtained by applying the coating approaches described in this section are summarized. The application of stimuli-responsive coatings is a very promising recent research trend and new highly effective methods, especially those based on the LbL application of smart polyelectrolyte shells, are expected to be exploited in the near future for the controlled release of corrosion inhibitors. However, polyelectrolyte shell application can involve the partial unloading of corrosion inhibitor from mesopores. This can be caused, for example, by the $\mathrm{pH}$ conditions during the shell formation, which may induce the release. This is the main reason why, in this case, it is particularly difficult to reach a high amount of loaded inhibitor.

\section{Corrosion inhibitor triggered release mechanisms}

As already showed in the previous section, the main reason why MSN are often functionalized or coated is to control the release of the loaded corrosion inhibitor. This is promoted by an external stimulus, which perturbs the equilibrium of the loaded nanoparticle and triggers the release of the active agent.

\section{pH-Sensitive systems}

One of the most exploited stimuli for corrosion inhibitors release is the $\mathrm{pH}$ variation. This triggering is very useful for metal substrates, whose corrosion usually proceeds generating anodic and cathodic regions, with consequent $\mathrm{pH}$ decrease or increase. Thus, the realization of nanostructures which involve $\mathrm{pH}$-responsive complexes allows the release of corrosion inhibitors in the corroded area; therefore, a $\mathrm{pH}$-sensitive system can induce a self-healing mechanism once the corrosion process starts. ${ }^{113}$ Researchers developed complex systems, tuning the nanocontainers responsiveness with respect to specific conditions, in order to promote the release of the corrosion inhibitors in those conditions typical of specific corrosion mechanisms. Therefore, different studies were focused on the optimization of the corrosion inhibitors release in acid $\mathrm{pH}$, alkaline $\mathrm{pH}$ or both of them. In particular, some release studies highlighted how $\mathrm{pH}$ affects the electrostatic interaction between MSN and the loaded corrosion inhibitor and therefore promotes or inhibits the corrosion inhibitor release from the MSN pores. ${ }^{54,113,147}$

Different release behaviours are reported on systems based on MBT-loaded MSN: Borisova et al. ${ }^{113}$ and Rahsepar et al. ${ }^{108}$ observed a higher release amount of MBT in alkaline conditions, due to the $\mathrm{pH}$ dependent solubility of MBT, while Maia et $a l^{51}$ and Chenan et al. ${ }^{104}$ verified a faster release in acid environment, due to the hydrolysis of an amount of nonfully hydrolysed TEOS, that, in acid ambient, further hydrolyses and unseals some pores, improving MBT release. They also observed that the maximum corrosion inhibitor release in corrosive environments is reached, after about 5 hours, due to both the solubility of MBT in the solution and the MBT degradation to sub-products, such as 2-hydroxybenzothiazole and benzothiazole. ${ }^{51,104,113}$ With a different approach, Amini et al. ${ }^{69}$ promoted the MBT release in neutral and alkaline conditions by exploiting the interaction between MBT with piperazine, previously grafted onto the MSN surface. 
A pH controlled release of 8-HQ from MSN was designed by Shchukina et al. ${ }^{106}$ and Shi et al., ${ }^{68}$ which demonstrated the stability of these nanocontainers at neutral and slightly acid or basic $\mathrm{pH}$ and the corrosion inhibitor release in stronger acid and alkaline environment. A similar behaviour was proposed by Kermannezhad et al., ${ }^{52}$ who reported an almost complete release of MBA at very low and high pH (over 80\%), an intermediate release at slightly acid or basic $\mathrm{pH}$ (around 60\%) and a very low release at neutral pH (after 50 h, 40\% of MBA was released).

Other alkaline pH-responsive nanocontainers were developed exploiting the instability of the bond $\mathrm{N}-\mathrm{Fe}$ in basic conditions with EBT as corrosion inhibitor, ${ }^{55}$ the trigger mechanism of pillararenes to activate the HMAP release ${ }^{133}$ and PSS/ PEI layers polyelectrolyte opening system which allows PAA release $^{144}$ and BYS. ${ }^{143}$ Alkaline ambient sensitive nanoparticles were also showed in another work, where MSN loaded with BTA and covered with PSS/PEI polyelectrolyte layers were developed. ${ }^{142}$

BTA is widely exploited in pH-responsive nanocontainers applications, ${ }^{105,119,140-142,145,152}$ due to the repulsive electrical force induced by moving from neutral $\mathrm{pH}$ to acid or basic pH. ${ }^{105}$ Therefore, BTA release is encouraged both in acid and in alkaline solutions, as reported by Borisova et al., ${ }^{105}$ who simply loaded BTA in MSN and observed the corrosion inhibitor release rate, and Grigoriev et al. ${ }^{145}$ who tested some $\mathrm{pH}$ responsive polyelectrolyte layers, made by PEI, BYS and poly (allylamine hydrochloride) (PAH) or poly(diallyldimethylammonium chloride) (PDADMAC) and molybdate. BTA was also released from MSN capped with TA-Fe complex by Qian et al. ${ }^{152}$ who revealed an increased corrosion inhibitor release with the acidification of the ambient, and from $\mathrm{Xu}$ et al., ${ }^{119}$ who realised a one-step synthesis and loading of MSN-BTA-CTAB nanoparticles (Fig. 9). In this paper, the authors observed that the CTAB presence in the MSN pores promotes the release in acid conditions, while, increasing the $\mathrm{pH}$ until basic values, the release rate was considerably decreased. CTAB did not allow the release in alkaline media and the release substantially started when the MSN were etched by the exposition to $\mathrm{OH}^{-}$ions.

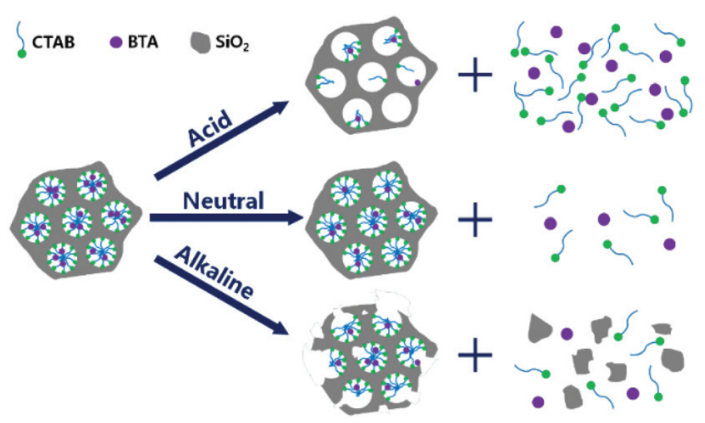

Fig. 9 Release mechanism from MSN-BTA-CTAB: release rate decreases with the increase of $\mathrm{pH}$. Reproduced under permission from ref. 119

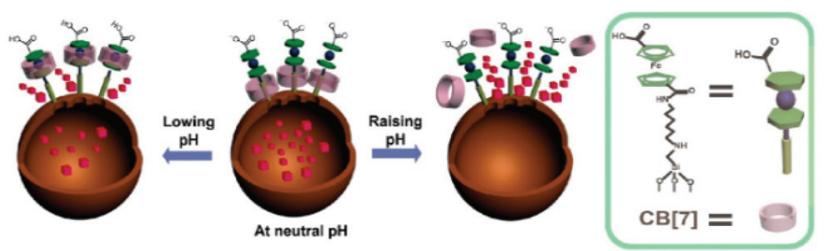

Fig. 10 Caffeine release from MSN functionalized with pseudorotaxane nanovalve. Adapted with permission from ref. 129. Copyright 2013 American Chemical Society.

Castaldo et $a .^{141}$ and Zheng et al. ${ }^{140}$ studied the kinetic release of BTA complexed with copper ions in acid conditions revealing, also in this case, the increasing in BTA release with the acidification. Wen et al. ${ }^{149}$ observed an encouraged alkaline release of BTA loaded in PEI covered MSN.

With the CB[7], HDA and FCDCA pseudorotaxane nanovalve installed on the MSN by $\mathrm{Fu}$ et al., ${ }^{129}$ encapsulated caffeine exploited the $\mathrm{pH}$-responsive system following the mechanism schematized in Fig. 10: at neutral $\mathrm{pH}$ the $\mathrm{CB}$ [7] acted as gatekeepers, while lowing or raising the $\mathrm{pH}$ the interactions between $\mathrm{CB}[7]$, HDA and FCDCA promoted the caffeine release. In particular, corrosion inhibitor release is highly encouraged toward very low or high $\mathrm{pH}$.

Chen et al. studied the release of BTA from surface modified MSN with $\mathrm{CB}[6]$ and cyclodextrin based nanovalves, developing different systems with tailored BTA release in both acid and alkaline conditions. ${ }^{130,131}$

\section{Other triggering mechanisms}

Electric potential variation triggered mechanisms. A supramolecular switch made of pillararenes onto $\mathrm{Fe}_{3} \mathrm{O}_{4}$ modified MSN encapsulating 8-HQ was developed by Ding et al. ${ }^{134}$ With the obtained nanocarriers they covered a magnesium alloy substrate and demonstrated that this supramolecular structure is sensitive to electric potential variations. Indeed, corrosion processes involve electric potential variations and, tuning the detachment of the pillararenes switch with the electric potential, the authors induced the corrosion inhibitor release from the MSN (see Fig. 11). Similar results were conducted by Wang et al. ${ }^{136}$ who developed redox-triggered nanoparticles activated by ferrocene moieties, using $\beta$-CD as capping system and CA as corrosion inhibitor onto an aluminium alloy substrate.

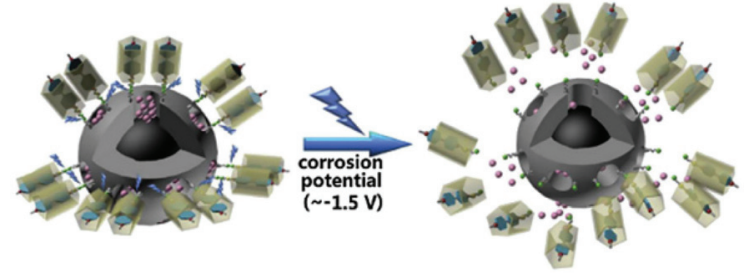

Fig. 11 Pillararenes supramolecular switches activation through corrosion potential variation. Reprinted with permission from ref. 134. Copyright 2017 American Chemical Society. 
Light-responsive switches. An interesting approach for inhibitors release is based on light-responsive smart nanocarriers. In contrast to $\mathrm{pH}$-sensitive systems, light stimulation is independent from the corrosion process, and therefore can be activated or deactivated on-demand.,142 The corrosion inhibitors release is induced by UV radiation in the smart nanocontainers developed by Chen et al. ${ }^{5}$ They exploited the cis/trans isomerization of azobenzene, which was grafted into HMSN loaded with BTA: in cis configuration, azobenzene allows the BTA release, while, in trans configuration, azobenzene closes the pores. They also showed how $\mathrm{pH}$ variation did not substantially modify BTA release amount and rate, while the UV irradiation allows the complete BTA release, which is inhibited if the nanocontainers are exposed to visible light. In an already mentioned Skorb's work, ${ }^{142}$ related to BTA release from MSN in alkaline media, they observed corrosion inhibitor release under IR laser irradiation, incorporating silver nanoparticles into polyelectrolyte layers outside the nanoparticles, in order to install light absorption dots (silver has very high surface resonance plasmon band). In this way, the BTA release amount was considerable higher with respect to the release obtained by simply exposing the nanocontainers to an alkaline solution.

Ion concentration triggers. Ion concentration change is also a trigger for corrosion inhibitor release. Maia et al. ${ }^{51,53}$ showed an increased release of loaded molecules from MSN into an aqueous solution with increasing the sodium chloride concentration, due to the interaction between corrosion inhibitor and $\mathrm{NaCl}$, which promotes the formation of sodium salts with higher solubility than pure corrosion inhibitor. Zheng et al. ${ }^{140}$ observed that the BTA-Cu complex is responsive to sulphide ions concentration variations, and it dissolves in response to the $\mathrm{Na}_{2} \mathrm{~S}$ concentration increase in an aqueous solution, therefore promoting the BTA release. Ding et al. ${ }^{133}$ realised a pillararenes nanovalve on HMAP loaded MSN which reacts with magnesium ions, creating a complex that interferes with the capping of the nanoparticles, inducing the corrosion inhibitor release.

Temperature influence on corrosion inhibitor release. As in light-dependant smart nanocarriers, temperature is an external parameter, not directly correlated to corrosion phenomena. However, several works include temperature-responsive silica nanocontainers. ${ }^{153,154}$ This trigger is not much investigated for corrosion applications and is usually connected to light irradiation. ${ }^{142}$ However, temperature can influence corrosion inhibitor release, as showed by Kermannezhad et al., ${ }^{52}$ who underlined the capability to modify the release of MBA from $\mathrm{pH}$-dependant MSN in response to a temperature variation of the surrounding environment, observing an increase in corrosion inhibitor release with the temperature increase.

Redox reactions release systems. Wang et al. ${ }^{136}$ developed a supramolecular switch made by ferrocene and $\beta$-CDs sensitive to redox stimuli, activated by cerium(Iv) salts (ceric ammonium nitrate, $\mathrm{H}_{8} \mathrm{~N}_{8} \mathrm{CeO}_{18}$ ) which were able to react with ferrocene, opening the nanovalve and inducing the CA release. They
Table 5 Triggering mechanisms for corrosion inhibitors release

\begin{tabular}{ll}
\hline Release mechanism trigger & Ref. \\
\hline $\mathrm{pH}$ & $51,52,54,55,68,69,104,105,106,108$, \\
& $113,119,129,130,131,133,140,141$, \\
& $142,143,144,145,147,149$ and 152 \\
Electrical potential & 134 and 136 \\
Light & 5 and 142 \\
Ion concentration & $51,53,133$ and 140 \\
Temperature & $52,142,153$ and 154 \\
Redox reaction & 128 and 136
\end{tabular}

observed an increase in CA release, increasing cerium concentration. Moreover, after redox reaction, cerium salts were reduced to cerium(III) salts, an inorganic corrosion inhibitor, generating a double anti-corrosive effect. In Sun's work, ${ }^{128}$ the redox stimulus was activated by dithiothreitol (DTT) with ZnO quantum dots (QDs), which acted as nanovalves outside the nanoparticles. They observed that the MBT amount and kinetics of release are promoted by the increase of DTT concentration. In Table 5 the triggering mechanisms above reported are summarized.

\section{MSN in smart anticorrosion coatings}

\section{Anticorrosive solutions: from passive barriers to smart nanostructured coatings}

Corrosion is a phenomenon whose related costs have been estimated as about $3-4 \%$ of the gross domestic production in Western Countries. On this basis, the global cost of corrosion can then be valued about USD 2.5 trillion per year. Using available mitigation strategies, a possible cost saving of $15-35 \%$ has been estimated, corresponding to USD 375-875 billion on a global basis. ${ }^{155}$ In this frame, protective polymer coatings are considered the main prevention and mitigation strategy to corrosion. $^{156}$

Most of the commercially available organic coatings exploit their protective function acting as a barrier layer towards pollutants. The history of these types of passive protective coatings is very ancient. ${ }^{157}$ One of the first examples of coatings based on organic materials was documented in $77 \mathrm{AD}$ by Pliny the Elder, who reported the use of a mixture containing tar to protect iron against rust. ${ }^{158}$

Adding additives to a polymer phase to impart functional properties to the coatings is a relatively new concept. A few years ago, additives were reported as possibly able to impart functional properties to the coatings in a number of ways that were not always proven beyond doubt. ${ }^{159}$ Instead, in the last years, nanotechnology applications in coatings have shown a remarkable growth. This was a result of the increased availability of nanoscale materials, such as various types of nanoparticles, as well as the development of interesting experimental approaches able to realize organic-inorganic hybrid coatings by exploiting the concept of preparation of nanoparticles by in situ sol-gel ${ }^{160,161}$ and the advancements in pro- 
cesses and characterization methods, that can control and validate the coating structure at the nanoscale. ${ }^{162-164}$

The use of nanoadditives in polymer coatings has been proposed in the years with objectives characterized by an even higher complexity. First, nanostructured additives have been used to improve the mechanical, thermomechanical and barrier properties of the coatings. For mechanical and thermomechanical properties, with a typical approach used in nanocomposites aimed at reducing the polymer chain mobility and increasing the elastic modulus of the polymer matrix, $0 \mathrm{D},{ }^{165}$ $1 \mathrm{D}^{166,167}$ and $2 \mathrm{D}^{168}$ nanostructured additives have been widely used. For barrier properties, the most relevant effects were obtained using 2D nanoadditives, such as lamellar clay, ${ }^{169,170}$ or graphene derivatives. ${ }^{171,172}$ Then, different types of nanoparticles were used to impart peculiar physical-chemical properties, such as hydrophobicity, ${ }^{173}$ UV blocking ${ }^{174}$ and antibacterial properties. ${ }^{175,176}$ In most cases the effectiveness of the smart coating was optimized by improving the nanoparticles dispersion into the coating and the nanoparticle/coating interfacial adhesion, key factors to obtain high performance nanocomposite materials. ${ }^{177-179}$ Also for MSN, relevant papers demonstrated that homogeneously distributed nanoparticles reduce the defects of the coatings, prolonging their physical barrier efficacy. ${ }^{129,133}$ For instance, Xie et al. ${ }^{124}$ showed that the addition of nanoparticles improved corrosion resistance because of the superior morphological features of the resulting coating, which was smoother and more homogeneous.

More recently a different strategy was exploited to maximize the properties of nanostructured coatings. In this new research line, the effort was not aimed at promoting the nanoparticle dispersion but their assembly in complex architectures. ${ }^{180-182}$

In parallel, in the last decade, in the coating sector, nanoparticles started to be considered not only as a way to tailor the properties of the matrices in which they were embedded through their optical, chemical and morphological features or their self-assembly capability. Indeed, the cargo capability of selected nanostructured materials found an always increasing interest for coating application. The idea of including within the coating a nanomaterial able to transport active agents and release them under stimuli, i.e. a nanocarrier, was very exciting and paved the way to the development of a new class of highly smart coating systems with incommensurable improved protection effectiveness and durability with respect to the passive coating systems.

In this frame, in the last years the research on the design of smart coatings containing various type on nanocarriers has undergone a significant increase. Nanocarriers are used in coatings for different purposes. First, they must release specific substances in situ, i.e. very close to the place where these active agents exploit their function. Thus, as already shown in the previous sections, the design of the nanocontainer plays a fundamental role to tailor the control of the active agent release in different conditions or under specific external stimuli. Moreover, they can protect the active agent from degradation, thus ensuring a long-lasting efficiency. ${ }^{32,141}$ Moreover, single nanocarriers or mixtures of different nano- carriers can exploit in coating multifunctional properties because they can show improved mechanical, thermomechanical and barrier properties and at the same time they can respond to several stimuli, protecting the substrate from chemical as well as physical damage via on-demand release of corrosion-inhibitors. ${ }^{183,184}$

Amongst different nanocarriers used in coating applications, recently MSN based coating are showing an even growing scientific interest. These advanced coating exploit most of the active agents' release mechanisms described and discussed in the previous sections.

Anticorrosive coatings may be based on alkyd resins, ${ }^{5,56,119,152}$ epoxy resins, ${ }^{59-61,108,113,115,122,149,150,185}$ eventually modified with amino hardener ${ }^{51}$ or mixed with polyamide ${ }^{68}$ or silicone,${ }^{69}$ polyesters, ${ }^{106,123,140}$ acrylic resins,${ }^{141}$ and polypyrrole. ${ }^{54,58}$ Sol-gel coatings are also investigated, obtained by TEOS and derivatives, such as (3-glycidyloxypropyl)trimethoxysilane (GPTMS), ${ }^{55,129,134,144}$ eventually functionalized with fluorine-containing monomers, ${ }^{133}$ methacryloxypropyltrimethoxysilane (MAPTS) ${ }_{147,148}$ or hybrid silane/zirconate coatings. ${ }^{104,105,114,131,136,142,143,145}$

Thus, the validation and characterization of these coating systems becomes crucial to critically evaluate the potential beneficial effects of mesoporous silica nanocarriers for anticorrosion applications and thus to identify the most promising perspectives in this still highly scattered research topic.

\section{Validation and optimization of MSN based anticorrosion coatings}

The validation of the performances of the anticorrosive systems is usually carried out on metallic substrates covered by smart coatings, i.e. coatings in which the functional MSN are embedded, or on model systems consisting of electrolyte solutions in which the functional MSN containing the active agents are dispersed.

In the case of smart coatings, the substrates are exposed to corrosive environment in controlled conditions in order to evaluate the evolution of specific physical parameters related to corrosion phenomena. Typical tests are conducted comparing the anticorrosive efficiency of the smart coatings with coatings containing the freely dispersed corrosion inhibitor, plain coatings and eventually uncoated samples. Although smart nanocontainers are studied to be theoretically able to prevent corrosion on each kind of metallic substrate, researchers usually projected their systems for specific applications, identifying a metal and characterizing the anticorrosive performances of their smart nanocarriers on specific substrates. Chosen substrates are typically those applied in fields such as aerospace, construction engineering and cultural heritage: several works included tests onto aluminium alloys, ${ }^{5,51,68,105,113,114,118,120,129,131,136,142,143,145,185}$ steel, $^{52,54,55,57-61,69,104,106,108,122,123,140,144,147,148,149,150,152}$ copper alloys $^{52,62,119,141}$ and magnesium alloys $5^{56,115,124,133,134}$ (Table 6).

As summarized in Table 6, the corrosion protection efficiency is evaluated by various analytical techniques, including electrochemical, morphological and spectroscopic tech- 
Table 6 Corrosion evaluation techniques

\begin{tabular}{|c|c|c|c|}
\hline Technique & Analytical technique & Substrate & Ref. \\
\hline \multirow{19}{*}{$\begin{array}{l}\text { Electrochemical } \\
\text { techniques }\end{array}$} & \multirow[t]{4}{*}{ Electrochemical impedance spectroscopy (EIS) } & $\mathrm{Al}$ alloy & $51,68,113,114,118,129,131,136$ and 185 \\
\hline & & $\mathrm{Cu}$ alloy & 52 and 62 \\
\hline & & Mg alloy & $56,115,124,133$ and 134 \\
\hline & & Steel & $\begin{array}{l}52,55,57,58,59,60,61,69,104,108,122,123,140, \\
144,149,150 \text { and } 152\end{array}$ \\
\hline & \multirow[t]{4}{*}{ Scanning vibrating electrode technique (SVET) } & $\mathrm{Al}$ alloy & $5,68,105,113,114,129,136,142,143,145$ and 185 \\
\hline & & $\mathrm{Cu}$ alloy & 119 \\
\hline & & $\mathrm{Mg}$ alloy & 133 and 134 \\
\hline & & Steel & 123,140 and 144 \\
\hline & $\begin{array}{l}\text { Localized electrochemical impedance } \\
\text { spectroscopy (LEIS) }\end{array}$ & Steel & 144 and 148 \\
\hline & \multirow[t]{2}{*}{ Potentiodynamic polarization (PDP) } & Mg alloy & 124 and 133 \\
\hline & & Steel & $52,57,69,108$ and 150 \\
\hline & \multirow{3}{*}{ Scanning Kelvin probe force microscopy (SKP) } & $\mathrm{Cu}$ alloy & 62 \\
\hline & & $\mathrm{Mg}$ alloy & 134 \\
\hline & & Steel & 147 and 148 \\
\hline & \multirow{2}{*}{ Salt spray test } & Al alloy & 68 \\
\hline & & Steel & 106 \\
\hline & Hydrogen evolution measurement & $\mathrm{Mg}$ alloy & 124 \\
\hline & Machu test & Al alloy & 113 \\
\hline & Electrochemical noise measurement (EN) & Steel & 60 \\
\hline \multirow[t]{17}{*}{ Morphological analyses } & \multirow[t]{4}{*}{ Optical microscopy } & Al alloy & $5,51,56,68,105,120$ and 129 \\
\hline & & $\mathrm{Cu}$ alloy & 141 \\
\hline & & $\mathrm{Mg}$ alloy & 134 \\
\hline & & Steel & $60,140,149$ and 152 \\
\hline & Surface profiler & Steel & 104 \\
\hline & \multirow[t]{2}{*}{ Three dimensional optical profilometer } & $\mathrm{Mg}$ alloy & 124 \\
\hline & & Steel & 147 and 148 \\
\hline & \multirow{4}{*}{ Scanning electron microscopy (SEM) } & $\mathrm{Al}$ alloy & $5,51,105,131,136,143$ and 145 \\
\hline & & $\mathrm{Cu}$ alloy & 119 and 141 \\
\hline & & $\mathrm{Mg}$ alloy & $56,115,124,133$ and 134 \\
\hline & & Steel & $54,55,58,59,60,61,69,104,106,108,123$ and 152 \\
\hline & \multirow[t]{2}{*}{ Focused ion beam (FIB) } & Al alloy & 136 \\
\hline & & $\mathrm{Mg}$ alloy & 134 \\
\hline & \multirow{4}{*}{ Atomic force microscopy (AFM) } & Al alloy & $5,105,129,131,142,143$ and 145 \\
\hline & & $\mathrm{Cu}$ alloy & 119 \\
\hline & & $\mathrm{Mg}$ alloy & 133 and 134 \\
\hline & & Steel & 55 \\
\hline \multirow{11}{*}{ Spectroscopic analyses } & \multirow[t]{4}{*}{ Energy dispersive X-ray analysis (EDX) } & Al alloy & $5,68,131$ and 136 \\
\hline & & $\mathrm{Cu}$ alloy & 141 \\
\hline & & Mg alloy & 56,124 and 134 \\
\hline & & Steel & $55,60,61,69$ and 104 \\
\hline & \multirow{2}{*}{ Fourier transform infrared spectroscopy (FTIR) } & $\mathrm{Mg}$ alloy & 115 \\
\hline & & Steel & 54,55 and 58 \\
\hline & \multirow[t]{2}{*}{$\mathrm{X}$-ray diffraction $(\mathrm{XRD})$} & $\mathrm{Mg}$ alloy & 56 \\
\hline & & Steel & 54 and 58 \\
\hline & \multirow[t]{2}{*}{ X-ray photoelectron spectroscopy (XPS) } & $\mathrm{Mg}$ alloy & 124 and 133 \\
\hline & & Steel & 59 \\
\hline & $\begin{array}{l}\text { Infrared reflection absorption spectroscopy } \\
\text { (IRRAS) }\end{array}$ & Al alloy & 143 \\
\hline
\end{tabular}

niques. Besides the corrosion progression, electrochemical techniques allow to determinate the efficacy of nanoparticles distribution onto the metal substrate, collecting electrical parameters (such as impedance in EIS or anodic and cathodic current in SVET), while morphological and spectroscopic analyses evaluate also the formation of protective compounds onto the metal surface and the self-healing properties of the coating. In fact, some authors evaluated the efficacy of a specific functionalization or the study of compounds produced during the corrosion process. Yeganeh et $a l^{61}$ confirmed by $\mathrm{XRD}$ the formation of protective compounds such as $\mathrm{MgF}_{2}$, induced by fluoride ions release onto a magnesium substrate, in contrast to the formation of $\mathrm{MgO}$ in absence of corrosion inhibitors, ${ }^{56}$ and $\mathrm{Fe}_{2}\left(\mathrm{MoO}_{4}\right)_{3}$ and other molybdenum oxides, due to Mo ions release which reacted with $\mathrm{Fe}$ of the steel surface. ${ }^{59}$ A similar result was obtained by Xie et al., ${ }^{124}$ which observed by XPS the presence of magnesium oxides $\mathrm{MgO}$ and $\mathrm{MgOH}$ on a magnesium substrate in absence of the corrosion inhibitors smart nanocarriers and the formation of $\mathrm{MgF}_{2}$, which improves corrosion resistance, in presence of the smart MSN.

Observing by SEM coatings containing embedded organic inhibitors, the amount of corrosive products after short time is generally low, ${ }^{105,114,133}$ in contrast to coatings doped with inorganic active molecules, which quickly react with the metal surface. ${ }^{54,56,59,136}$ Alipour et al. ${ }^{57}$ motived the MPTMS 
functionalization of MSN asserting that the functionalization improves the barrier properties of the coating, reducing its porosity, and enhances the adhesion to the metal substrate, increasing the coating hydrophobicity. Moreover, an hydrophobic functionalization can directly improve the barrier properties of the coatings, thus reducing the corrosion rate of the treated substrate. ${ }^{133}$

Hollamby et al. $^{123}$ improved the MSN dispersion in a polyester-based coating by functionalizing the nanoparticles with OTES. Moreover, they underlined that free dispersed BTA in the polyester coating is not effective in preventing corrosion phenomena due to the BTA interactions with the polymer network during the curing step, while the use of corrosion inhibitors nanocarriers, such as MSN, inhibits the BTA interaction with the polymer network and enables an improved corrosion protection. MSN act as smart reservoir of inhibitors, and they do not affect adhesion and barrier properties of the coating.

Several works report that at early times of exposure to corrosive environments the use of MSN as smart nanocarriers may not give a substantial advantage with respect to the use of free inhibitor, owing to slow inhibitor release. ${ }^{5,51,124,129,134,136}$ Nevertheless, MSN show significant advantage in corrosion protection at long-time observation, providing higher durability of the active coating. Moreover, MSN also act as a shield from UV radiation for the loaded molecules. For example, Castaldo et $a .^{141}$ demonstrated that the use of MSN as smart nanocarriers of corrosion inhibitors allows to prolong the durability of metal protective coatings, protecting the corrosion inhibitors from possible photodegradation.

Moreover, corrosion resistance of coatings containing MSN can be tailored by optimizing the quantity and size of embedded MSN as well as the amount of encapsulated inhibitor and the evaluation of the coating barrier properties can be independent from the corrosion inhibition. The optimal amount of MSN to be embedded into coatings depends on the specific tested system but, generally, electrochemical measurements show that $1-4 \mathrm{wt} \%$ are the maximum amount of nanocontainers able to provide corrosion inhibition. ${ }^{108,115}$

Borisova et al. $^{113}$ explored the corrosion resistance behaviour of MBT loaded MSN tuning the MBT loading and the nanoparticles dimensions. Fixing the anticorrosion inhibitor loading at about $20 \%$ by weight within the nanocarriers, they considering two sizes ( $80 \mathrm{~nm}$ and $700 \mathrm{~nm}$ diameter), and they found that for both particle size also very low MSN amounts, such as $0.04 \mathrm{wt} \%$, are able to induce an increased corrosion resistance of the coatings. Moreover, they also evaluated $1.7 \mathrm{wt} \%$ as an upper limit composition for the bigger MSN (700 nm). Above this amount, barrier properties of the coating dramatically fail, with loss of the coating durability due to an easy penetration of corrosive media that easily reach the metal substrate. This phenomenon is due to the increased presence of defects into the coating. The compromise between good corrosion inhibition and barrier properties was found at $0.7 \mathrm{wt} \%$ of MSN with $80 \mathrm{~nm}$ diameter. ${ }^{185}$ Moreover, they also proposed the application of two overlapped protective coatings on metal substrates, embedding MSN only in one of the coatings and founding that the selective localization of MSN in the coating closer to the metal surface improves the protection from corrosion, while the best barrier properties were observed when MSN were included in the external coating. Finally, embedding MSN in the external coating layer at $0.5-0.7 \mathrm{wt} \%$ loading amount provided the optimal result in terms of corrosion inhibition/barrier properties balance. ${ }^{114}$

\section{Conclusions and perspectives}

As shown in the previous sections, MSN find large application potentialities for the realization of effective anticorrosive coatings. Within this broad topic, in this review 3 main research subtopics have been identified and discussed:

(a) The synthesis of MSN with tailored porosity and structure;

(b) The design and development of corrosion inhibitor gate/release mechanisms;

(c) The use of MSN in smart anticorrosive coatings and the validation of the coating performances.

As concerning the synthesis, MSN with tailored size and size distribution and with controlled pore size and geometry are currently widely investigated. Nevertheless, based on the analysis of the literature, further research is still needed with the following specific objectives:

(a1) To optimize the synthesis of MSN, developing sustainable, high yield/high throughput processes;

(a2) To optimize one-step synthesis/functionalization/ loading processes that will reduce the production costs of MSN, a limiting factor for several applications;

(a3) To set up viable procedures to realize MSN with maximized cargo capability of active agents, such as MSN with an inner reservoir and a mesoporous shell (hollow MSN), with optimized size and volume ratio between the core and the shell.

For the development of the loading/gate/release mechanisms, research performed so far have been focused on the design and test of gating systems with different degrees of complexity, including physical adsorption of the active agents in the mesopores, covalent grafting of the active agents, formation of stable chelating complexes of the active agents, physical capping of the pores with various chemical species (nanovalves, polyelectrolytes). Together with a specific gating system, each research has usually proposed a corresponding stimuli-responsive mechanism able to promote the ondemand release of corrosion inhibitors in response to the variation of physical parameters. The most investigated triggers to promote the release of anticorrosion agents are changes of $\mathrm{pH}$, ions concentration, electrical potential and light irradiation. Due to the specificity of the proposed gating/release mechanisms, a comparison between the different approached proposed is very hard. Each approach has peculiarities that make it highly effective in response to a specific stimulus. Very interesting are the gating/release mechanisms based on $\mathrm{pH}$ respon- 
sive chelating complexes and on layer-by-layer polyelectrolytes. In this frame, the most interesting research perspectives should address to:

(b1) Maximize the loading efficiency of active agents, still limited also due to the partial release of the actives during the successive application of the gating system; in fact, often, more than $70 \%$ of the pore volume of the particles is unexploited in the available research works, thus underestimating the cargo potentiality and then the effectiveness of MSN;

(b2) Develop new and even more effective gating/release mechanisms, properly designed for new class of active agents, in particular bio-based and sustainable anticorrosion agents;

(b3) Develop gating/release mechanisms properly designed for specific target applications (protection of metals, alloys and concretes in buildings and marine environments, transportation and aeronautics, cultural heritage).

Finally, for the embedding of MSN in coatings to realize smart anticorrosion systems, current researches are mainly focused on the optimization of the relative amount of MSN and their effective dispersion within the coatings and on the validation of the smart coatings through different methods. In this frame, the most promising research trends and perspectives are:

(c1) The optimization of the gating/release mechanism and the release kinetics of the active agents within the coating, as the release mechanisms and kinetics are usually optimized on nanoparticles dispersed in model systems (mainly water dispersions);

(c2) The promotion of the self-assembly of the nanoparticles in specific morphologies, to optimize the release of the active agents in the exact place in which they are needed;

(c3) The realization of smart coatings embedding different MSN loaded with different anticorrosion agents, in this way reproducing the approach adopted in commercial anticorrosion products, that usually contain mixtures of different of active agents;

(c4) The optimization of the interfacial adhesion between the particles and the matrix to guarantee high mechanical and barrier properties of the coatings that, synergistically combined with the stimuli-responsive release of the active agents, should be able to ensure the best corrosion protection;

(c5) The development of highly effective multifunctional smart coatings in which, in addition to the passive barrier and the stimuli-responsive release of the active agents, the coatings would be able to entrap or deactivate the corrosive agents before they enter in contact with the substrate to be protected;

(c6) The development of reversible smart coatings, with self-healing properties based on reversible mechanisms of formation/opening of dynamic bonds;

(c7) The development of smart environmentally sustainable and safe-by-design smart coatings, based on renewable materials, and realized following the main paradigms of the circular economy.

Thus, this review demonstrates that there is here certainly plenty of scope for improvement in the field of MSN and their use in smart anticorrosive coatings. Following the identified research trends and perspectives, or developing new breakthrough approaches to exploit the highly interesting properties of MSN, can pave the way to the development of a new class of smart anticorrosive coatings with extraordinarily superior properties with respect to current commercial products used in different sectors (cultural heritage, civil and industrial infrastructures, transportations and airspace), thus contributing to preserve our past history and culture and to protect our future.

\section{Conflicts of interest}

There are no conflicts to declare.

\section{Acknowledgements}

This work has been carried out within the InnovaConcrete project funded by the European Union's Horizon 2020 Research and Innovation Programme under the grant agreement no. 760858 .

\section{References}

1 Z. Liu, P. H. Chong, A. N. Butt, P. Skeldon and G. E. Thompson, Corrosion mechanism of laser-melted AA 2014 and AA 2024 alloys, Appl. Surf. Sci., 2005, 247, 294-299.

2 A. S. H. Makhlouf, Handbook of smart coatings for materials protection, Elsevier, Woodhead Publishing Limited, UK, 2014.

3 W. J. Clark, J. D. Ramsey, R. L. McCreery and G. S. Frankel, A Galvanic Corrosion Approach to Investigating Chromate Effects on Aluminum Alloy 2024-T3, J. Electrochem. Soc., 2002, 149, B179-B185.

4 R. L. Twite and G. P. Bierwagen, Review of alternatives to chromate for corrosion protection of aluminum aerospace alloys, Prog. Org. Coat., 1998, 33, 91-100.

5 T. Chen, R. Chen, Z. Jin and J. Liu, Engineering hollow mesoporous silica nanocontainers with molecular switches for continuous self-healing anticorrosion coating, J. Mater. Chem. A, 2015, 3(18), 9510-9516.

$6 \mathrm{X} . \mathrm{Hu}, \mathrm{Y}$. Wang and B. Peng, Chitosan-capped mesoporous silica nanoparticles as $\mathrm{pH}$-responsive nanocarriers for controlled drug release, Chem. - Asian J., 2014, 9(1), 319-327.

7 S. Motahar, N. Nikkam, A. A. Alemrajabi, R. Khodabandeh, M. S. Toprak and M. Muhammed, A novel phase change material containing mesoporous silica nanoparticles for thermal storage: a study on thermal conductivity and viscosity, Int. Commun. Heat Mass Transfer, 2014, 56, 114-120.

8 Y. Chen, X. Zhang, B. Wang, M. Lv, Y. Zhu and J. Gao, Fabrication and characterization of novel shape-stabilized stearic acid composite phase change materials with 
tannic-acid-templated mesoporous silica nanoparticles for thermal energy storage, RSC Adv., 2017, 7(26), 1562515631.

9 J. Yin, E. S. Kim, J. Yang and B. Deng, Fabrication of a novel thin-film nanocomposite (TFN) membrane containing MCM-41 silica nanoparticles (NPs) for water purification, J. Membr. Sci., 2012, 423, 238-246.

10 A. K. Sinha, K. Suzuki, M. Takahara, H. Azuma, T. Nonaka and K. Fukumoto, Mesostructured Manganese Oxide/Gold Nanoparticle Composites for Extensive Air Purification, Angew. Chem., Int. Ed., 2007, 46(16), 2891-2894.

11 R. Castaldo, R. Avolio, M. Cocca, G. Gentile, M. E. Errico, M. Avella, C. Carfagna and V. Ambrogi, A Versatile Synthetic Approach toward Hyper-Cross-Linked StyreneBased Polymers and Nanocomposites, Macromolecules, 2017, 50(11), 4132-4143.

12 R. Castaldo, V. Ambrogi, R. Avolio, M. Cocca, G. Gentile, M. E. Errico and M. Avella, Functional hyper-crosslinked resins with tailored adsorption properties for environmental applications, Chem. Eng. J., 2019, 362, 497-503.

13 R. Castaldo, R. Avolio, M. Cocca, G. Gentile, M. E. Errico, M. Avella, C. Carfagna and V. Ambrogi, Synthesis and adsorption study of hyper-crosslinked styrene-based nanocomposites containing multi-walled carbon nanotubes, RSC Adv., 2017, 7(12), 6865-6874.

14 M. Guerritore, R. Castaldo, B. Silvestri, R. Avolio, M. Cocca, M. E. Errico, M. Avella, G. Gentile and V. Ambrogi, Hyper-Crosslinked Polymer Nanocomposites Containing Mesoporous Silica Nanoparticles with Enhanced Adsorption Towards Polar Dyes, Polymers, 2020, 12(6), 1388.

15 C. Perego and R. Millini, Porous materials in catalysis: challenges for mesoporous materials, Chem. Soc. Rev., 2013, 42, 3956-3976.

16 X. Yang, D. Chen, S. Liao, H. Song, Y. Li, Z. Fu and Y. Su, High-performance $\mathrm{Pd}-\mathrm{Au}$ bimetallic catalyst with mesoporous silica nanoparticles as support and its catalysis of cinnamaldehyde hydrogenation, J. Catal., 2012, 291, 3643.

17 E. I. W. Crossland, N. Noel, V. Sivaram, T. Leijtens, J. A. Alexander-Webber and H. J. Snaith, Mesoporous TiO2 single crystals delivering enhanced mobility and optoelectronic device performance, Nature, 2013, 495, 215219.

18 B. Li, X. Yang, L. Xia, M. I. Majeed and B. Tan, Hollow microporous organic capsules, Sci. Rep., 2013, 3, 2128.

19 Y. Song, Y. Li, Q. Xu and Z. Liu, Mesoporous silica nanoparticles for stimuli-responsive controlled drug delivery: advances, challenges, and outlook, Int. J. Nanomed., 2017, $12,87$.

20 D. G. Shchukin and H. Möhwald, Smart nanocontainers as depot media for feedback active coatings, Chem. Commun., 2011, 47(31), 8730-8739.

21 M. Manzano and M. Vallet-Regí, Mesoporous silica nanoparticles for drug delivery, Adv. Funct. Mater., 2020, 30(2), 1902634.
22 M. Yeganeh, M. Omidi, S. H. H. Mortazavi, A. Etemad, M. H. Nazari and S. M. Marashi, Application of mesoporous silica as the nanocontainer of corrosion inhibitor, Corrosion Protection at the Nanoscale, Elsevier, 2020, pp. 275-294.

23 X. Liu, W. Li, W. Wang, L. Song, W. Fan, X. Gao and C. Xiong, Synthesis and characterization of $\mathrm{pH}$-responsive mesoporous chitosan microspheres loaded with sodium phytate for smart water-based coatings, Mater. Corros., 2018, 69(6), 736-748.

24 K. Zhang, L. L. Xu, J. G. Jiang, N. Calin, K. F. Lam, S. J. Zhang, H. H. Wu, G. D. Wu, B. Albela, L. Bonnevoit and P. Wu, Facile Large-Scale Synthesis of Monodisperse Mesoporous Silica Nanospheres with Tunable Pore Structure, J. Am. Chem. Soc., 2013, 135(7), 2427-2430.

25 D. H. Everett, Manual of Symbols and Terminology for Physicochemical Quantities and Units, Appendix II: Definitions, Terminology and Symbols in Colloid and Surface Chemistry, Pure Appl. Chem., 1972, 31, 577-638.

$26 \mathrm{Z}$. Wu and D. Zhao, Ordered mesoporous materials as adsorbents, Chem. Commun., 2011, 47(12), 3332-3338.

27 R. Castaldo, G. Gentile, M. Avella, C. Carfagna and V. Ambrogi, Microporous Hyper-Crosslinked Polystyrenes and Nanocomposites with High Adsorption Properties: A Review, Polymers, 2017, 9, 651.

28 F. Balas, M. Manzano, M. Colilla and M. Vallet-Regí, L-Trp adsorption into silica mesoporous materials to promote bone formation, Acta Biomater., 2008, 4(3), 514-522.

29 F. Tang, L. Li and D. Chen, Mesoporous silica nanoparticles: synthesis, biocompatibility and drug delivery, Adv. Mater., 2012, 24(12), 1504-1534.

30 M. Vallet-Regi, A. Ramila, R. P. Del Real and J. PérezPariente, A new property of MCM-41: drug delivery system, Chem. Mater., 2001, 13(2), 308-311.

31 N. Y. Abu-Thabit and A. S. Hamdy, Stimuli-responsive polyelectrolyte multilayers for fabrication of self-healing coatings-a review, Surf. Coat. Technol., 2016, 303, 406-424.

32 L. Zhang, S. Qiao, Y. Jin, L. Cheng, Z. Yan and G. Q. Lu, Hydrophobic functional group initiated helical mesostructured silica for controlled drug release, Adv. Funct. Mater., 2008, 18(23), 3834-3842.

33 Y. Gao, Y. Chen, X. Ji, X. He, Q. Yin, Z. Zhang, J. Shi and Y. Li, Controlled intracellular release of doxorubicin in multidrug-resistant cancer cells by tuning the shell-pore sizes of mesoporous silica nanoparticles, ACS Nano, 2011, 5(12), 9788-9798.

34 E. Aznar, L. Mondragón, J. V. Ros-Lis, F. Sancenón, M. D. Marcos, R. Martínez-Máñez, J. Soto, E. Perez-Paya and P. Amorós, Finely tuned temperature-controlled cargo release using paraffin-capped mesoporous silica nanoparticles, Angew. Chem., Int. Ed., 2011, 50(47), 1117211175.

35 M. Salzano de Luna, G. G. Buonocore, C. Giuliani, E. Messina, G. Di Carlo, M. Lavorgna, L. Ambrosio and G. M. Ingo, Long-Lasting Efficacy of Coatings for Bronze Artwork Conservation: The Key Role of Layered Double 
Hydroxide Nanocarriers in Protecting Corrosion Inhibitors from Photodegradation, Angew. Chem., Int. Ed., 2018, 57(25), 7380-7384.

36 B. G. Trewyn, I. I. Slowing, S. Giri, H. T. Chen and V. S. Y. Lin, Synthesis and functionalization of a mesoporous silica nanoparticle based on the sol-gel process and applications in controlled release, Acc. Chem. Res., 2007, 40(9), 846-853.

37 J. M. Rosenholm, C. Sahlgren and M. Lindén, Towards multifunctional, targeted drug delivery systems using mesoporous silica nanoparticles-opportunities \& challenges, Nanoscale, 2010, 2(10), 1870-1883.

38 L. Minati, V. Antonini, M. Dalla Serra, G. Speranza, F. Enrichi and P. Riello, pH-activated doxorubicin release from polyelectrolyte complex layer coated mesoporous silica nanoparticles, Microporous Mesoporous Mater., 2013, 180, 86-91.

39 F. B. Zanardi, I. A. Barbosa, P. C. de Sousa Filho, L. D. Zanatta, D. L. da Silva, O. A. Serra and Y. Iamamoto, Manganese porphyrin functionalized on Fe3O4@nSiO2@MCM-41 magnetic composite: Structural characterization and catalytic activity as cytochrome P450 model, Microporous Mesoporous Mater., 2016, 219, 161-171.

40 A. Popat, S. B. Hartono, F. Stahr, J. Liu, S. Z. Qiao and G. Q. Lu, Mesoporous silica nanoparticles for bioadsorption, enzyme immobilisation, and delivery carriers, Nanoscale, 2011, 3(7), 2801-2818.

41 E. Pérez-Esteve, M. Ruiz-Rico, C. de la Torre, E. Llorca, F. Sancenón, M. D. Marcos, P. Amoros, C. Guillem, R. Martinez-Manez and J. M. Barat, Stability of different mesoporous silica particles during an in vitro digestion, Microporous Mesoporous Mater., 2016, 230, 196207.

42 W. Stöber, A. Fink and E. Bohn, Controlled growth of monodisperse silica spheres in the micron size range, J. Colloid Interface Sci., 1968, 26(1), 62-69.

43 C. S. Ha and S. S. Park, General synthesis and physicochemical properties of mesoporous materials, Periodic Mesoporous Organosilicas, Springer, 2019, pp. 15-85.

44 Y. Yamada and K. Yano, Synthesis of monodispersed super-microporous/mesoporous silica spheres with diameters in the low submicron range, Microporous Mesoporous Mater., 2006, 93(1-3), 190-198.

45 M. Sivanandini, S. S. Dhami, B. S. Pabla and M. K. Gupta, Effect of 3-mercaptopropyltrimethoxysilane on Surface Finish and Material Removal Rate in Chemical Mechanical Polishing, Procedia Mater. Sci., 2014, 6, 528537.

46 Q. Cai, W. Y. Lin, F. S. Xiao, W. Q. Pang, X. H. Chen and B. S. Zou, The preparation of highly ordered MCM-41 with extremely low surfactant concentration, Microporous Mesoporous Mater., 1999, 32(1-2), 1-15.

47 T. Yokoi, H. Yoshitake and T. Tatsumi, Synthesis of amino-functionalized MCM-41 via direct co-condensation and post-synthesis grafting methods using mono-, di- and tri-amino-organoalkoxysilanes, J. Mater. Chem., 2004, 14(6), 951-957.

48 D. R. Radu, C. Y. Lai, J. Huang, X. Shu and V. S. Y. Lin, Fine-tuning the degree of organic functionalization of mesoporous silica nanosphere materials via an interfacially designed co-condensation method, Chem. Commun., 2005, 10, 1264-1266.

49 D. Zhao, J. Feng, Q. Huo, N. Melosh, G. H. Fredrickson, B. F. Chmelka and G. D. Stucky, Triblock copolymer syntheses of mesoporous silica with periodic 50 to 300 angstrom pores, Science, 1998, 279(5350), 548-552.

$50 \mathrm{H}$. Chen, J. He, H. Tang and C. Yan, Porous silica nanocapsules and nanospheres: dynamic self-assembly synthesis and application in controlled release, Chem. Mater., 2008, 20(18), 5894-5900.

51 F. Maia, J. Tedim, A. D. Lisenkov, A. N. Salak, M. L. Zheludkevich and M. G. Ferreira, Silica nanocontainers for active corrosion protection, Nanoscale, 2012, 4(4), 1287-1298.

52 K. Kermannezhad, A. N. Chermahini, M. M. Momeni and B. Rezaei, Application of amine-functionalized MCM-41 as $\mathrm{pH}$-sensitive nano container for controlled release of 2-mercaptobenzoxazole corrosion inhibitor, Chem. Eng. J., 2016, 306, 849-857.

53 F. Maia, J. Tedim, A. C. Bastos, M. G. S. Ferreira and M. L. Zheludkevich, Nanocontainer-based corrosion sensing coating, Nanotechnology, 2013, 24(41), 415502.

54 M. Saremi and M. Yeganeh, Application of mesoporous silica nanocontainers as smart host of corrosion inhibitor in polypyrrole coatings, Corros. Sci., 2014, 86, 159-170.

55 S. M. Ashrafi-Shahri, F. Ravari and D. Seifzadeh, Smart organic/inorganic sol-gel nanocomposite containing functionalized mesoporous silica for corrosion protection, Prog. Org. Coat., 2019, 133, 44-54.

56 M. Yeganeh and M. Saremi, Corrosion inhibition of magnesium using biocompatible Alkyd coatings incorporated by mesoporous silica nanocontainers, Prog. Org. Coat., 2015, 79, 25-30.

57 K. Alipour and F. Nasirpouri, Smart anti-corrosion selfhealing zinc metal-based molybdate functionalized-mesoporous-silica (MCM-41) nanocomposite coatings, RSC Adv., 2017, 7(82), 51879-51887.

58 M. Yeganeh, M. Saremi and H. Rezaeyan, Corrosion inhibition of steel using mesoporous silica nanocontainers incorporated in the polypyrrole, Prog. Org. Coat., 2014, 77(9), 1428-1435.

59 M. Yeganeh and A. Keyvani, The effect of mesoporous silica nanocontainers incorporation on the corrosion behavior of scratched polymer coatings, Prog. Org. Coat., 2016, 90, 296-303.

60 M. Yeganeh, M. Omidi and T. Rabizadeh, Anti-corrosion behavior of epoxy composite coatings containing molybdate-loaded mesoporous silica, Prog. Org. Coat., 2019, 126, 18-27.

61 M. Yeganeh, N. Asadi, M. Omidi and M. Mahdavian, An investigation on the corrosion behavior of the epoxy 
coating embedded with mesoporous silica nanocontainer loaded by sulfamethazine inhibitor, Prog. Org. Coat., 2019, 128, 75-81.

62 X. Ma, L. Xu, W. Wang, Z. Lin and X. Li, Synthesis and characterisation of composite nanoparticles of mesoporous silica loaded with inhibitor for corrosion protection of Cu-Zn alloy, Corros. Sci., 2017, 120, 139-147.

63 C. Zea, R. Barranco-García, J. Alcántara, J. Simancas, M. Morcillo and D. de la Fuente, pH-dependent release of environmentally friendly corrosion inhibitor from mesoporous silica nanoreservoirs, Microporous Mesoporous Mater., 2018, 255, 166-173.

64 C. Zea, R. Barranco-García, B. Chico, I. Díaz, M. Morcillo and D. De La Fuente, Smart Mesoporous Silica Nanocapsules as Environmentally Friendly Anticorrosive Pigments, Int. J. Corros., 2015, 2015, 1-8.

65 Y. Chen, H. Chen, L. Guo, Q. He, F. Chen, J. Zhou, J. Feng and J. Shi, Hollow/rattle-type mesoporous nanostructures by a structural difference-based selective etching strategy, ACS Nano, 2010, 4(1), 529-539.

66 A. Liberman, N. Mendez, W. C. Trogler and A. C. Kummel, Synthesis and surface functionalization of silica nanoparticles for nanomedicine, Surf. Sci. Rep., 2014, 69(2-3), 132-158.

67 S. Iqbal and J. I. Yun, EDTA-functionalized mesoporous silica for the removal of corrosion products: adsorption studies and performance evaluation under gamma irradiation, Microporous Mesoporous Mater., 2017, 248, 149-157.

68 H. Shi, L. Wu, J. Wang, F. Liu and E. H. Han, Submicrometer mesoporous silica containers for active protective coatings on AA 2024-T3, Corros. Sci., 2017, 127, 230-239.

69 M. Amini, R. Naderi, M. Mahdavian and A. Badiei, Effect of Piperazine Functionalization of Mesoporous Silica Type SBA-15 on the Loading Efficiency of 2-Mercaptobenzothiazole Corrosion Inhibitor, Ind. Eng. Chem. Res., 2020, 59(8), 3394-3404.

70 Y. Tozuka, A. Wongmekiat, K. Kimura, K. Moribe, S. Yamamura and K. Yamamoto, Effect of pore size of FSM-16 on the entrapment of flurbiprofen in mesoporous structures, Chem. Pharm. Bull., 2005, 53(8), 974-977.

71 T. W. Kim, P. W. Chung and V. S. Y. Lin, Facile synthesis of monodisperse spherical MCM-48 mesoporous silica nanoparticles with controlled particle size, Chem. Mater., 2010, 22(17), 5093-5104.

72 M. Benjelloun, P. Van Der Voort, P. Cool, O. Collart and E. F. Vansant, Reproducible synthesis of high quality MCM-48 by extraction and recuperation of the gemini surfactant, Phys. Chem. Chem. Phys., 2001, 3(1), 127-131.

73 S. Wang and H. Li, Structure directed reversible adsorption of organic dye on mesoporous silica in aqueous solution, Microporous Mesoporous Mater., 2006, 97(1-3), 21-26.

74 D. Zhao, Y. Wan and W. Zhou, Ordered mesoporous materials, John Wiley \& Sons, 2012.
75 T. Heikkilä, J. Salonen, J. Tuura, M. S. Hamdy, G. Mul, N. Kumar, T. Salmi, D. Y. Murzin, L. Laitinen, A. M. Kaukonen, J. Hirvonen and V. P. Lehto, Mesoporous silica material TUD-1 as a drug delivery system, Int. J. Pharm., 2007, 331(1), 133-138.

76 A. B. D. Nandiyanto, S. G. Kim, F. Iskandar and K. Okuyama, Synthesis of spherical mesoporous silica nanoparticles with nanometer-size controllable pores and outer diameters, Microporous Mesoporous Mater., 2009, 120(3), 447-453.

77 C. Boissiere, M. Kümmel, M. Persin, A. Larbot and E. Prouzet, Spherical MSU-1 mesoporous silica particles tuned for HPLC, Adv. Funct. Mater., 2001, 11(2), 129-135.

78 F. Hoffmann, M. Cornelius, J. Morell and M. Fröba, Silica-based mesoporous organic-inorganic hybrid materials, Angew. Chem., Int. Ed., 2006, 45(20), 3216-3251.

79 S. H. Wu, C. Y. Mou and H. P. Lin, Synthesis of mesoporous silica nanoparticles, Chem. Soc. Rev., 2013, 42(9), 3862-3875.

80 F. Caruso, R. A. Caruso and H. Möhwald, Nanoengineering of inorganic and hybrid hollow spheres by colloidal templating, Science, 1998, 282(5391), 11111114.

81 M. Chen, L. Wu, S. Zhou and B. You, A method for the fabrication of monodisperse hollow silica spheres, $A d v$. Mater., 2006, 18(6), 801-806.

82 B. Tan and S. E. Rankin, Dual latex/surfactant templating of hollow spherical silica particles with ordered mesoporous shells, Langmuir, 2005, 21(18), 8180-8187.

83 Y. M. Bai, J. Mao, D. X. Li, X. J. Luo, J. Chen, F. R. Tay and L. N. Niu, Bimodal antibacterial system based on quaternary ammonium silane-coupled core-shell hollow mesoporous silica, Acta Biomater., 2019, 85, 229-240.

84 M. M. Titirici, A. Thomas and M. Antonietti, Replication and coating of silica templates by hydrothermal carbonization, Adv. Funct. Mater., 2007, 17(6), 1010-1018.

85 J. Zhou, W. Wu, D. Caruntu, M. H. Yu, A. Martin, J. F. Chen, C. J. O'Connor and W. L. Zhou, Synthesis of porous magnetic hollow silica nanospheres for nanomedicine application, J. Phys. Chem. C, 2007, 111(47), 17473-17477.

86 E. Prouzet, F. Cot, C. Boissière, P. J. Kooyman and A. Larbot, Nanometric hollow spheres made of MSU-Xtype mesoporous silica, J. Mater. Chem., 2002, 12(5), 15531556.

87 J. Liu, F. Fan, Z. Feng, L. Zhang, S. Bai, Q. Yang and C. Li, From hollow nanosphere to hollow microsphere: mild buffer provides easy access to tunable silica structure, J. Phys. Chem. C, 2008, 112(42), 16445-16451.

88 M. Mandal and M. Kruk, Family of single-micelle-templated organosilica hollow nanospheres and nanotubes synthesized through adjustment of organosilica/surfactant ratio, Chem. Mater., 2012, 24(1), 123-132.

89 J. J. Yuan, O. O. Mykhaylyk, A. J. Ryan and S. P. Armes, Cross-linking of cationic block copolymer micelles by 
silica deposition, J. Am. Chem. Soc., 2007, 129(6), 17171723.

90 D. Liu, M. Sasidharan and K. Nakashima, Micelles of poly (styrene-b-2-vinylpyridine-b-ethylene oxide) with blended polystyrene core and their application to the synthesis of hollow silica nanospheres, J. Colloid Interface Sci., 2011, 358(2), 354-359.

91 H. P. Hentze, S. R. Raghavan, C. A. McKelvey and E. W. Kaler, Silica hollow spheres by templating of catanionic vesicles, Langmuir, 2003, 19(4), 1069-1074.

92 D. H. Hubert, M. Jung, P. M. Frederik, P. H. H. Bomans, J. Meuldijk and A. L. German, Vesicle-Directed Growth of Silica, Adv. Mater., 2000, 12(17), 1286-1290.

93 H. Wang, Y. Wang, X. Zhou, L. Zhou, J. Tang, J. Lei and C. Yu, Siliceous Unilamellar Vesicles and Foams by Using Block-Copolymer Cooperative Vesicle Templating, Adv. Funct. Mater., 2007, 17(4), 613-617.

94 A. Lind, B. Spliethoff and M. Lindén, Unusual, vesicle-like patterned, mesoscopically ordered silica, Chem. Mater., 2003, 15(3), 813-818.

95 Q. Sun, P. J. Kooyman, J. G. Grossmann, P. H. H. Bomans, P. M. Frederik, P. C. M. M. Magusin, T. P. M. Beelen, R. A. van Santen and N. A. J. M. Sommerdijk, The formation of well-defined hollow silica spheres with multilamellar shell structure, Adv. Mater., 2003, 15(13), 10971100.

96 H. Wang, P. Chen and X. Zheng, Hollow permeable polysiloxane capsules: a novel approach for fabrication, guest encapsulation and morphology studies, J. Mater. Chem., 2004, 14(10), 1648-1651.

97 Y. Wan and S. H. Yu, Polyelectrolyte controlled large-scale synthesis of hollow silica spheres with tunable sizes and wall thicknesses, J. Phys. Chem. C, 2008, 112(10), 36413647.

98 Y. Lu, H. Fan, A. Stump, T. L. Ward, T. Rieker and C. J. Brinker, Aerosol-assisted self-assembly of mesostructured spherical nanoparticles, Nature, 1999, 398(6724), 223-226.

99 X. Jiang, T. L. Ward, Y. S. Cheng, J. Liu and C. J. Brinker, Aerosol fabrication of hollow mesoporous silica nanoparticles and encapsulation of L-methionine as a candidate drug cargo, Chem. Commun., 2010, 46(17), 30193021.

100 Y. Li, N. Li, W. Pan, Z. Yu, L. Yang and B. Tang, Hollow mesoporous silica nanoparticles with tunable structures for controlled drug delivery, ACS Appl. Mater. Interfaces, 2017, 9(3), 2123-2129.

101 W. A. El-Said, A. S. Moharram, E. M. Hussein and A. M. El-Khawaga, Design, synthesis, anticorrosion efficiency, and applications of novel Gemini surfactants for preparation of small-sized hollow spheres mesoporous silica nanoparticles, Mater. Chem. Phys., 2018, 211, 123136.

102 H. Zhang, H. Xu, M. Wu, Y. Zhong, D. Wang and Z. Jiao, A soft-hard template approach towards hollow mesoporous silica nanoparticles with rough surfaces for controlled drug delivery and protein adsorption, J. Mater. Chem. B, 2015, 3(31), 6480-6489.

103 Y. Zhu, J. Shi, W. Shen, H. Chen, X. Dong and M. Ruan, Preparation of novel hollow mesoporous silica spheres and their sustained-release property, Nanotechnology, 2005, 16(11), 2633.

104 A. Chenan, S. Ramya, R. P. George and U. K. Mudali, 2Mercaptobenzothiazole-loaded hollow mesoporous silicabased hybrid coatings for corrosion protection of modified 9Cr-1Mo ferritic steel, Corrosion, 2014, 70(5), 496511.

105 D. Borisova, H. Möhwald and D. G. Shchukin, Mesoporous silica nanoparticles for active corrosion protection, ACS Nano, 2011, 5(3), 1939-1946.

106 E. Shchukina, D. Shchukin and D. Grigoriev, Effect of inhibitor-loaded halloysites and mesoporous silica nanocontainers on corrosion protection of powder coatings, Prog. Org. Coat., 2017, 102, 60-65.

107 E. Albert, N. Cotolan, N. Nagy, G. Sáfrán, G. Szabó, L. M. Mureşan and Z. Hórvölgyi, Mesoporous silica coatings with improved corrosion protection properties, Microporous Mesoporous Mater., 2015, 206, 102-113.

108 M. Rahsepar, F. Mohebbi and H. Hayatdavoudi, Synthesis and characterization of inhibitor-loaded silica nanospheres for active corrosion protection of carbon steel substrate, J. Alloys Compd., 2017, 709, 519-530.

109 I. Recloux, Y. Gonzalez-Garcia, M. E. Druart, F. Khelifa, P. Dubois, J. M. C. Mol and M. G. Olivier, Active and passive protection of AA2024-T3 by a hybrid inhibitor doped mesoporous sol-gel and top coating system, Surf. Coat. Technol., 2016, 303, 352-361.

110 I. Recloux, M. Mouanga, M. E. Druart and M. G. Olivier, Silica mesoporous thin films as containers for benzotriazole for corrosion protection of 2024 aluminium alloys, Appl. Surf. Sci., 2015, 346, 124-133.

111 W. C. Changjean, L. Y. Huang, P. Y. Liu and T. C. Tsai, Repairable mesoporous silica film with replenishing corrosion inhibitor as corrosion protection layer of aluminum alloy, Microporous Mesoporous Mater., 2014, 192, 8288.

112 C. Giuliani, M. Pascucci, C. Riccucci, E. Messina, M. Salzano de Luna, M. Lavorgna, G. M. Ingo and G. Di Carlo, Chitosan-based coatings for corrosion protection of copper-based alloys: a promising more sustainable approach for cultural heritage applications, Prog. Org. Coat., 2018, 122, 138-146.

113 D. Borisova, D. Akçakayıran, M. Schenderlein, H. Möhwald and D. G. Shchukin, Nanocontainer-based anticorrosive coatings: effect of the container size on the self-healing performance, Adv. Funct. Mater., 2013, 23(30), 3799-3812.

114 D. Borisova, H. Möhwald and D. G. Shchukin, Influence of embedded nanocontainers on the efficiency of active anticorrosive coatings for aluminum alloys part II: influence of nanocontainer position, ACS Appl. Mater. Interfaces, 2013, 5(1), 80-87. 
115 Y. Qiao, W. Li, G. Wang, X. Zhang and N. Cao, Application of ordered mesoporous silica nanocontainers in an anticorrosive epoxy coating on a magnesium alloy surface, $R S C$ Adv., 2015, 5(59), 47778-47787.

116 Y. H. Liu, J. B. Xu, J. T. Zhang and J. M. Hu, Electrodeposited silica film interlayer for active corrosion protection, Corros. Sci., 2017, 120, 61-74.

117 J. M. Falcón, L. M. Otubo and I. V. Aoki, Highly ordered mesoporous silica loaded with dodecylamine for smart anticorrosion coatings, Surf. Coat. Technol., 2016, 303, 319-329.

118 R. Noiville, O. Jaubert, M. Gressier, J. P. Bonino, P. L. Taberna, B. Fori and M. J. Menu, Ce(III) corrosion inhibitor release from silica and boehmite nanocontainers, J. Mater. Sci. Eng. B, 2018, 229, 144-154.

119 J. B. Xu, Y. Q. Cao, L. Fang and J. M. Hu, A one-step preparation of inhibitor-loaded silica nanocontainers for selfhealing coatings, Corros. Sci., 2018, 140, 349-362.

120 X. Jiang, Y. B. Jiang, N. Liu, H. Xu, S. Rathod, P. Shah and C. J. Brinker, Controlled release from core-shell nanoporous silica particles for corrosion inhibition of aluminum alloys, J. Nanomater., 2011, 2011, 760237.

121 Z. Zheng, M. Schenderlein, X. Huang, N. J. Brownbill, F. Blanc and D. Shchukin, Influence of functionalization of nanocontainers on self-healing anticorrosive coatings, ACS Appl. Mater. Interfaces, 2015, 7(41), 22756-22766.

122 A. Keyvani, M. Yeganeh and H. Rezaeyan, Application of mesoporous silica nanocontainers as an intelligent host of molybdate corrosion inhibitor embedded in the epoxy coated steel, Prog. Nat. Sci.: Mater. Int., 2017, 27(2), 261267.

123 M. J. Hollamby, D. Fix, I. Dönch, D. Borisova, H. Möhwald and D. Shchukin, Hybrid polyester coating incorporating functionalized mesoporous carriers for the holistic protection of steel surfaces, Adv. Mater., 2011, 23(11), 13611365.

124 Z. H. Xie, D. Li, Z. Skeete, A. Sharma and C. J. Zhong, Nanocontainer-enhanced self-healing for corrosion-resistant Ni coating on $\mathrm{Mg}$ alloy, ACS Appl. Mater. Interfaces, 2017, 9(41), 36247-36260.

125 Y. Zhao, J. B. Xu, J. Zhan, Y. Q. Chen and J. M. Hu, Electrodeposited superhydrophobic mesoporous silica films co-embedded with template and corrosion inhibitor for active corrosion protection, Appl. Surf. Sci., 2020, 508, 145242.

126 N. Song and Y. W. Yang, Molecular and supramolecular switches on mesoporous silica nanoparticles, Chem. Soc. Rev., 2015, 44(11), 3474-3504.

127 V. Marturano, H. Marcille, P. Cerruti, N. A. Bandeira, M. Giamberini, A. Trojanowska, B. Tylkowski, C. Carfagna, G. Ausanio and V. Ambrogi, Visible-light responsive nanocapsules for wavelength-selective release of natural active agents, ACS Appl. Nano Mater., 2019, 2(7), 4499-4506.

128 S. Sun, X. Zhao, M. Cheng, Y. Wang, C. Li and S. Hu, Facile preparation of redox-responsive hollow mesoporous silica spheres for the encapsulation and controlled release of corrosion inhibitors, Prog. Org. Coat., 2019, 136, 105302.

129 J. Fu, T. Chen, M. Wang, N. Yang, S. Li, Y. Wang and $\mathrm{X}$. Liu, Acid and alkaline dual stimuli-responsive mechanized hollow mesoporous silica nanoparticles as smart nanocontainers for intelligent anticorrosion coatings, ACS Nano, 2013, 7(12), 11397-11408.

130 T. Chen and J. Fu, pH-responsive nanovalves based on hollow mesoporous silica spheres for controlled release of corrosion inhibitor, Nanotechnology, 2012, 23(23), 235605.

131 T. Chen and J. Fu, An intelligent anticorrosion coating based on pH-responsive supramolecular nanocontainers, Nanotechnology, 2012, 23(50), 505705.

132 M. Wang, T. Chen, C. Ding and J. Fu, Mechanized silica nanoparticles based on reversible bistable [2] pseudorotaxanes as supramolecular nanovalves for multistage $\mathrm{pH}$ controlled release, Chem. Commun., 2014, 50(39), 50685071.

133 C. Ding, Y. Liu, M. Wang, T. Wang and J. Fu, Self-healing, superhydrophobic coating based on mechanized silica nanoparticles for reliable protection of magnesium alloys, J. Mater. Chem. A, 2016, 4(21), 8041-8052.

134 C. Ding, J. Xu, L. Tong, G. Gong, W. Jiang and J. Fu, Design and fabrication of a novel stimulusfeedback anticorrosion coating featured by rapid selfhealing functionality for the protection of magnesium alloy, ACS Appl. Mater. Interfaces, 2017, 9(24), 2103421047.

135 T. Chen, N. Yang and J. Fu, Controlled release of cargo molecules from hollow mesoporous silica nanoparticles based on acid and base dual-responsive cucurbit [7] uril pseudorotaxanes, Chem. Commun., 2013, 49(58), 65556557.

136 T. Wang, L. Tan, C. Ding, M. Wang, J. Xu and J. Fu, Redoxtriggered controlled release systems-based bi-layered nanocomposite coating with synergistic self-healing property, J. Mater. Chem. A, 2017, 5(4), 1756-1768.

137 E. Abdullayev and Y. Lvov, Clay nanotubes for corrosion inhibitor encapsulation: release control with end stoppers, J. Mater. Chem., 2010, 20(32), 6681-6687.

138 E. Abdullayev and Y. Lvov, Halloysite clay nanotubes for controlled release of protective agents, J. Nanosci. Nanotechnol., 2011, 11(11), 10007-10026.

139 E. Abdullayev, R. Price, D. Shchukin and Y. Lvov, Halloysite tubes as nanocontainers for anticorrosion coating with benzotriazole, ACS Appl. Mater. Interfaces, 2009, 1(7), 1437-1443.

140 Z. Zheng, X. Huang, M. Schenderlein, D. Borisova, R. Cao, H. Möhwald and D. Shchukin, Self-Healing and antifouling multifunctional coatings based on $\mathrm{pH}$ and sulfide ion sensitive nanocontainers, Adv. Funct. Mater., 2013, 23(26), 3307-3314.

141 R. Castaldo, M. Salzano de Luna, C. Siviello, G. Gentile, M. Lavorgna, E. Amendola and M. Cocca, On the acidresponsive release of benzotriazole from engineered 
mesoporous silica nanoparticles for corrosion protection of metal surfaces, J. Cult. Herit., 2020, 44, 317-324.

142 E. V. Skorb, A. G. Skirtach, D. V. Sviridov, D. G. Shchukin and H. Möhwald, Laser-controllable coatings for corrosion protection, ACS Nano, 2009, 3(7), 1753-1760.

143 E. V. Skorb, D. Fix, D. V. Andreeva, H. Möhwald and D. G. Shchukin, Surface-Modified Mesoporous SiO2 Containers for Corrosion Protection, Adv. Funct. Mater., 2009, 19(15), 2373-2379.

144 T. Siva, S. Mayavan, S. S. Sreejakumari and S. Sathiyanarayanan, Mesoporous silica based reservoir for the active protection of mild steel in an aggressive chloride ion environment, RSC Adv., 2015, 5(49), 3927839284.

145 D. O. Grigoriev, K. Köhler, E. Skorb, D. G. Shchukin and H. Möhwald, Polyelectrolyte complexes as a "smart" depot for self-healing anticorrosion coatings, Soft Matter, 2009, 5(7), 1426-1432.

146 C. Zea, J. Alcántara, R. Barranco-García, M. Morcillo and D. De la Fuente, Synthesis and characterization of hollow mesoporous silica nanoparticles for smart corrosion protection, Nanomaterials, 2018, 8(7), 478.

147 C. Zea, R. Barranco-García, J. Alcántara, B. Chico, M. Morcillo and D. de la Fuente, Hollow mesoporous silica nanoparticles loaded with phosphomolybdate as smart anticorrosive pigment, J. Coat. Technol. Res., 2017, 14(4), 869-878.

148 C. Zea, J. Alcántara, R. Barranco-García, J. Simancas, M. Morcillo and D. de la Fuente, Anticorrosive behavior study by localized electrochemical techniques of sol-gel coatings loaded with smart nanocontainers, J. Coat. Technol. Res., 2017, 14(4), 841-850.

149 J. Wen, J. Lei, J. Chen, L. Liu, X. Zhang and L. Li, Polyethylenimine wrapped mesoporous silica loaded benzotriazole with high $\mathrm{pH}$-sensitivity for assembling selfhealing anti-corrosive coatings, Mater. Chem. Phys., 2020, 253, 123425.

150 H. Wang, M. Gan, L. Ma, T. Zhou, H. Wang, S. Wang, W. Dai and X. Sun, Synthesis of polyaniline-modified mesoporous-silica containers for anticorrosion coatings via in-situ polymerization and surface-protected etching, Polym. Adv. Technol., 2016, 27(7), 929-937.

151 S. H. Sonawane, B. A. Bhanvase, A. A. Jamali, S. K. Dubey, S. S. Kale, D. V. Pinjari, R. D. Kulkarni, P. R. Gogate and A. B. Pandit, Improved active anticorrosion coatings using layer-by-layer assembled $\mathrm{ZnO}$ nanocontainers with benzotriazole, Chem. Eng. J., 2012, 189, 464-472.

152 B. Qian, M. Michailidis, M. Bilton, T. Hobson, Z. Zheng and D. Shchukin, Tannic complexes coated nanocontainers for controlled release of corrosion inhibitors in selfhealing coatings, Electrochim. Acta, 2019, 297, 1035-1041.

153 P. Yang, S. Gai and J. Lin, Functionalized mesoporous silica materials for controlled drug delivery, Chem. Soc. Rev., 2012, 41(9), 3679-3698.

154 G. L. Li, Z. Zheng, H. Möhwald and D. G. Shchukin, Silica/polymer double-walled hybrid nanotubes: synthesis and application as stimuli-responsive nanocontainers in self-healing coatings, ACS Nano, 2013, 7(3), 2470-2478.

155 G. Koch, Cost of corrosion, in Trends in oil and gas corrosion research and technologies, Production and Transmission, ed. A. M. El-Sherik, Woodhead Publishing Series in Energy, 2017, pp. 3-30.

156 P. A. Sørensen, S. Kiil, K. Dam-Johansen and C. E. Weinell, Anticorrosive coatings: a review, J. Coat. Technol. Res., 2009, 6(2), 135-176.

157 R. R. Myers, History of coatings science and technology, J. Macromol. Sci., Chem., 1981, 15(6), 1133-1149.

158 M. Kendig and D. J. Mills, An historical perspective on the corrosion protection by paints, Prog. Org. Coat., 2017, 102, 53-59.

159 S. B. Lyon, R. Bingham and D. J. Mills, Advances in corrosion protection by organic coatings: What we know and what we would like to know, Prog. Org. Coat., 2017, 102, 27.

160 L. Mascia, L. Prezzi, G. D. Wilcox and M. Lavorgna, Molybdate doping of networks in epoxy-silica hybrids: Domain structuring and corrosion inhibition, Prog. Org. Coat., 2006, 56(1), 13-22.

161 L. Mascia, L. Prezzi and M. Lavorgna, Peculiarities in the solvent absorption characteristics of epoxy-siloxane hybrids, Polym. Eng. Sci., 2005, 45(8), 1039-1048.

162 R. H. Fernando, Nanocomposite and nanostructured coatings: Recent advancements, in Nanotechnology Applications in Coatings, ACS Symposium Series, 1008, American Chemical Society, 2009, ch. 1, pp 2-21.

163 M. Mihelčič, M. Gaberšček, G. Di Carlo, C. Giuliani, M. Salzano de Luna, M. Lavorgna and A. K. Surca, Influence of silsesquioxane addition on polyurethanebased protective coatings for bronze surfaces, Appl. Surf. Sci., 2019, 467-468, 912-925.

164 R. Castaldo, G. C. Lama, P. Aprea, G. Gentile, V. Ambrogi, M. Lavorgna and P. Cerruti, Humidity-Driven Mechanical and Electrical Response of Graphene/Cloisite Hybrid Films, Adv. Funct. Mater., 2019, 29, 1807744.

165 M. Avella, M. E. Errico and G. Gentile, PMMA Based Nanocomposites Filled with Modified $\mathrm{CaCO}_{3}$ Nanoparticles, Macromol. Symp., 2007, 247(1), 140-146.

166 M. Lavorgna, V. Romeo, A. Martone, M. Zarrelli, M. Giordano, G. G. Buonocore, M. Z. Qu, G. X. Fei and H. S. Xia, Silanization and silica enrichment of multiwalled carbon nanotubes: Synergistic effects on the thermal-mechanical properties of epoxy nanocomposites, Eur. Polym. J., 2013, 49(2), 428-438.

167 P. Russo, M. Lavorgna, F. Piscitelli, D. Acierno and L. Di Maio, Thermoplastic polyurethane films reinforced with carbon nanotubes: the effect of processing on the structure and mechanical properties, Eur. Polym. J., 2013, 49(2), 379-388.

168 N. Taheri and S. Sayyahi, Effect of clay loading on the structural and mechanical properties of organoclay/HDIbased thermoplastic polyurethane nanocomposites, $e$ Polymers, 2016, 16(1), 65-73. 
169 D. J. Voorn, W. Ming and A. M. van Herk, Nanotechnology Applications in Coatings, ACS Symp. Ser., 2009, 1008(2), 24-35.

170 D. J. Voorn, W. Ming and A. M. van Herk, Clay platelets encapsulated inside latex particles, Macromolecules, 2006, 39(14), 4654-4656.

171 R. Castaldo, G. C. Lama, P. Aprea, G. Gentile, M. Lavorgna, V. Ambrogi and P. Cerruti, Effect of the oxidation degree on self-assembly, adsorption and barrier properties of nano-graphene, Microporous Mesoporous Mater., 2018, 260, 102-115.

172 N. Yan, G. G. Buonocore, M. Lavorgna, S. Kaciulis, S. K. Balijepalli, Y. Zhan, H. Xia and L. Ambrosio, The role of reduced graphene oxide on chemical, mechanical and barrier properties of natural rubber composites, Compos. Sci. Technol., 2014, 102, 74-81.

173 V. Di Tullio, M. Cocca, R. Avolio, G. Gentile, N. Proietti, P. Ragni, M. E. Errico, D. Capitani and M. Avella, Unilateral NMR investigation of multifunctional treatments on stones based on colloidal inorganic and organic nanoparticles, Magn. Reson. Chem., 2014, 53(1), 64-77.

174 K. Girigoswami, M. Viswanathan, R. Murugesan and A. Girigoswami, Studies on polymer-coated zinc oxide nanoparticles: UV-blocking efficacy and in vivo toxicity, Mater. Sci. Eng., C, 2015, 56, 501-510.

175 M. Lavorgna, I. Attianese, G. G. Buonocore, A. Conte, M. A. Del Nobile, F. Tescione and E. Amendola, MMT-supported $\mathrm{Ag}$ nanoparticles for chitosan nanocomposites: structural properties and antibacterial activity, Carbohydr. Polym., 2014, 102, 385-392.

176 M. Cocca and L. D’Orazio, Novel silver/polyurethane nanocomposite by in situ reduction: Effects of the silver nanoparticles on phase and viscoelastic behavior, J. Polym. Sci., Part B: Polym. Phys., 2008, 46(4), 344-350.

177 R. Avolio, G. Gentile, M. Avella, D. Capitani and M. E. Errico, Synthesis and characterization of poly (methylmethacrylate)/silica nanocomposites: Study of the interphase by solid-state NMR and structure/properties relationships, J. Polym. Sci., Part A: Polym. Chem., 2010, 48(23), 5618-5629.

178 F. Piscitelli, G. G. Buonocore, M. Lavorgna, L. Verdolotti, S. Pricl, G. Gentile and L. Mascia, Peculiarities in the
structure-Properties relationship of epoxy-silica hybrids with highly organic siloxane domains, Polymer, 2015, 63, 222-229.

179 A. De Nicola, R. Avolio, F. Della Monica, G. Gentile, M. Cocca, C. Capacchione, M. E. Errico and G. Milano, Rational design of nanoparticle/monomer interfaces: a combined computational and experimental study of in situ polymerization of silica based nanocomposites, RSC Adv. , 2015, 5(87), 71336-71340.

180 G. Scherillo, M. Lavorgna, G. G. Buonocore, Y. H. Zhan, H. S. Xia, G. Mensitieri and L. Ambrosio, Tailoring assembly of reduced graphene oxide nanosheets to control gas barrier properties of natural rubber nanocomposites, ACS Appl. Mater. Interfaces, 2014, 6(4), 22302234.

181 M. Salzano De Luna, Y. Wang, T. Zhai, L. Verdolotti, G. G. Buonocore, M. Lavorgna and H. Xia, Nanocomposite polymeric materials with $3 \mathrm{D}$ graphene-based architectures: from design strategies to tailored properties and potential applications, Prog. Polym. Sci., 2019, 89, 213249.

182 F. He, G. Mensitieri, M. Lavorgna, M. Salzano de Luna, G. Filippone, H. Xia, R. Esposito and G. Scherillo, Tailoring gas permeation and dielectric properties of bromobutyl rubber-Graphene oxide nanocomposites by inducing an ordered nanofiller microstructure, Composites, Part B, 2017, 116, 361-368.

183 U. B. Bagale, S. H. Sonawane, B. Bhanvase, V. S. Hakke, M. Kakunuri, S. Manickam and S. S. Sonawane, Multifunctional coatings based on smart nanocontainers, in Advances in Smart Coatings and Thin Films for Future Industrial and Biomedical Engineering Applications, ed. A. S. H. Makhlouf and N. Y. Abu-Thabit, Elsevier, Amsterdam, 2020, pp. 132-160.

184 M. A. Deyab, Anticorrosion properties of nanocomposites coatings: A critical review, J. Mol. Liq., 2020, 113533.

185 D. Borisova, H. Möhwald and D. G. Shchukin, Influence of Embedded Nanocontainers on the Efficiency of Active Anticorrosive Coatings for Aluminum Alloys Part I: Influence of Nanocontainer Concentration, ACS Appl. Mater. Interfaces, 2017, 4(6), 2931-2939. 